\title{
Iron-bearing minerals from soils developing on volcanic materials from Southern Chile:Application in heterogeneous catalysis
}

\author{
Carmen Pizarro ${ }^{1,2 *}$, Mauricio Escudey ${ }^{1,2}$, Manuel Gacitúa ${ }^{1}$, José Domingos Fabris ${ }^{3,4}$
}

${ }^{1}$ Facultad de Química y Biología, USACH, Av. L.B. O’Higgins 3363, Santiago, 7254758, Chile. ${ }^{2}$ Centro para el Desarrollo de la Nanociencia y Nanotecnología (CEDENNA), Av. L.B. O’Higgins 3363, Santiago, 7254758, Chile. ${ }^{3}$ Universidade Federal dos Vales do Jequitinhonha e Mucuri (UFVJM), Campus JK, 39100-000 Diamantina, Minas Gerais, Brazil. ${ }^{4}$ Departamento de Química- ICEx, Federal Universidade Federal de Minas Gerais, Campus - Pampulha, 31270-901 Belo Horizonte, Minas Gerais, Brazil.

Corresponding author: *carmen.pizarro@usach.cl

\begin{abstract}
Chilean soils derived from volcanic ashes are a natural source of iron oxides. Due to their properties, mineralogy, and surface characteristics, iron oxides from Chilean soils are potential candidates for technological applications such as heterogeneous catalysis. However, before a direct application in catalysis, pre-treatment methods are necessary to concentrate iron oxides from bulk volcanic soils. Here, we provide a comprehensive review of pre-treatment strategies for iron oxide concentration including physical separation and selective chemical dissolutive methods for application in catalytic processes, such as the water gas shift (WGS) and Fenton reactions. For preparation of WGS catalyst from volcanic soils, thermal treatment has been demonstrated to be effective, yielding enhanced results for Andisols compared to Ultisols. Based on mineralogical characterisation, it seems that WGS reaction efficiency depends on mineralogical phase shift and the changes of $\mathrm{Fe}^{2+} / \mathrm{Fe}^{3+}$ ratio, produced through heating. In addition, Ultisols have shown as efficient catalysts in Fenton and Fenton-like processes, after application of physical and chemical pre-treatments to different size-fractions of the soil sample, improving the yield performance of catalysts. Magnetic separates from the Ultisol sand fraction (compared to the silt+clay fractions) demonstrate the best catalytic performance as Fenton reagent due to their natural magnetite and titanomagnetite content. Application of $\mathrm{NaOH}$ selective dissolutive treatment to silt+clay fraction of volcanic soils also produces Fenton and Fenton-like catalyst with improved performance. Our review indicates that catalytic performance can be explained not only by the iron oxide mineral content but also by their characteristics and magnetic properties. The application of the appropriate physical and chemical pre-treatment methods can modulate and enhance the catalytic capabilities of iron oxides from volcanic soils.
\end{abstract}

Keywords: Iron oxide minerals, water gas shift reaction, Fenton reaction, Selective dissolutive treatments, magnetic separation. 


\section{Technological applications of natural iron oxides}

Volcanic soils have been used to create novel materials with diverse technological applications, including soil-component stabilization, pollutant adsorption (immobilisation), and degradation. For example, Navia et al. (2005) reported that Chilean volcanic soils are a good candidate for mineral landfill liner material applications due to their high heavy metal retention (comparable to natural zeolite). Calabi-Floody et al. (2009) reviewed the application of nanostructured clays from volcanic-derived materials to a range of different technologies. More recently, Calabi-Floody et al. (2015) reported the use of nanoclays extracted from Andisols for organic carbon stabilization. In this regard, volcanic soils are known to possess significant amounts of iron oxides present as different mineral structures with varied morphologies, particle size distribution, and aggregate formation. Due to their properties and roles in the soil matrix, particularly with respect to the physiochemical reactivity of soils, natural iron oxide minerals have numerous environmental and industrial applications. Goure-Doubi et al. (2014) established the important role of iron oxides in the creation of building bridges between fulvic/humic substances and the mineral fraction in soil. Another important role of iron oxide minerals in soil, as established by Cornell and Schwertmann (1996), corresponds to the contribution of variable surface charge from less crystalline iron oxides, such as ferrihydrite, a well-known highly reactive iron oxide (Lan et al. 2017). In more interdisciplinary studies, Braunschweig et al. (2013) and Liu et al. (2014), have established that depending on the type of mineral, particle size, crystalline degree, presence of organic matter, and aggregation, iron oxides from soil may control several inorganic, organic, and microbiological redox reactions, participating in the natural cycles of several elements. Furthermore, as Pereira et al. (2007 and 2012) reported, iron oxides have been extensively characterized for their decontamination capacities of organic pollutants; e.g., iron oxide on nanometricallophane particles have shown efficient degrading capacities of organic molecules. Moreover, Yu et al. (2016) employed a batch-reactor system with hematite, goethite, and ferrihydrite for the degradation of nitrobenzene/anisole on soil samples. Taken together, these works demonstrate how the transforming capacities intrinsic to natural iron oxides have been utilized in an array of remediation applications.

The technological applications of iron oxides are inspired by their known properties, principally those related to surface characteristics and redox reactivity. Taking advantage of these properties and the overall low solubility of these minerals, other types of iron-oxide-based technology have been developed: heterogeneous catalysts. In their review, Oliveira et al. (2013) highlighted that iron oxides are renowned heterogeneous catalysts for chemical and industrial processes. For example, the production of $\mathrm{NH}_{3}$ through the Haber process (Haber and Le Rossignol, 1916) makes use of iron-oxide based catalyst. Moreover, while hydrocarbon (fuel) synthesis through the Fischer-Tropsch process is typically catalysed by ruthenium, iron oxides have also shown good performance (de Smit and Weckhuysen 2008) at comparatively lower cost. Additional examples of iron oxides as heterogeneous catalysts include photocatalytic degradation of pollutants using a hematite-based catalyst (Xiang et al. 2016) or feroxyhyte (Lima et al. 2015), and Advanced Oxidation Processes (AOP) through the Fenton and Fenton-like reactions (Nidheesh, 2015; Pereira et al. 2012; Garrido-Ramirez et al. 2010 and 2013). Finally, hydrogen production through the Water Gas Shift (WGS) reaction has shown good performance in high-temperature conditions using a Fe-based catalyst (Zhu et al. 2016). 
Thus, there are many publications demonstrating the utility of iron oxides in remediation systems in environmental and industrial applications. Only very few of these reports, however, address the application of iron oxides from natural sources, such as volcanic soils, where both the unique properties of these soils and their natural iron oxide content may result in potential technological applications. In fact, searching for "iron oxide" in the online search engine Scopus (Scopus 2017) and filtering results with the terms "heterogeneous catalysis" and "mineral" yields only 1,061 results, representing articles published from 1980 to 2017. Of these, only 20 (ca. 1.9\%) actually correspond to original research articles with examples of natural iron oxides, iron containing soil-fractions, and soils applications on heterogeneous catalysis (Table 1).

Among the most important advantages of using natural iron materials as catalysts are their overall low cost and ubiquity, as iron is the fourth most abundant element in the earth's crust (Pereira et al. 2012). As detailed in Table 1, the most abundant applications are related to the Fenton and Fenton-like reaction processes. Previously, Escudey and Moya (1989), Moya et al. (1991a), and Pizarro et al. (2005) reported the application of Chilean volcanic soils as WGS reaction catalysts, which will be further reviewed herein. When iron oxides from natural sources are used in catalytic applications, their intrinsic characteristics, including the presence of different mineral structures with varied morphologies, size distribution, and aggregate formation, affect their performance and hinder repeatable results. The most common explanation is the presence of other soil constituents, such as organic matter, that may interfere with iron oxide active sites. Further, dominance of a poorly crystalline mineral layer may have a detrimental effect on the catalytic potential intrinsic of some minerals, such as magnetite. For instance, Vicente et al. (2011) established that in situ application of Fenton reagents from soils with higher organic matter yielded lower reaction efficiency. Kwan and Voelker (2003) compared iron-based catalysts for organic compound oxidation, revealing that ferrihydrite, a short-range iron oxide mineral, exhibited the lowest efficiency. In addition, Filip et al. (2007) natural ferrihydrite nanoparticles found on seepage waters of a complex-ore mine-tailing have shown catalytic capabilities for $\mathrm{HOOH}$ decompositions comparable to commercially accessible $\mathrm{FeO}(\mathrm{OH})$ catalyst. In light of these observations, we begin our review of heterogeneous catalysis application in Chilean volcanic soils with a discussion of the main properties that might exert a positive or negative effect on catalytic performance. Among the different types of volcanic soils present in Chile, Andisols and Ultisols are the most important (The Twelve Orders of Soil Taxonomy, 2006). Properties such as dominant iron oxide mineralogy, $\mathrm{pH}$, organic carbon (OC), isoelectric point (IEP), cation exchange capacity (CEC), and iron oxide content distribution are summarized in Table 2 (Mella and Kühne 1985; Pizarro et al. 2003; Escudey et al. 2004; Pizarro et al. 2017).

Andisols are less developed than Ultisols, with a mineral content of poorer crystalline degree (Mella and Kühne 1985). These soils orders have distinct dominant iron oxide minerals originating from their main inorganic precursor material: volcanic ash. Silva et al. (2014) described the presence of Ca-magnetite as the most important iron oxide minerals, besides Fediopside, in ashes from the Osorno volcano, establishing a probable explanation for the mineral profiles in soils derived from volcanic ashes. The iron oxide mineralogy of Chilean volcanic soils has been thoroughly characterized, and, at least for Ultisol, a trend has been observed regarding the iron oxide mineralogy of the different size-fractions of soil (Pizarro et al. 2017). Pizarro et al. (2001) reported that magnetic separated from the sand-size soil fraction of Ultisol as partially oxidized magnetite. In contrast, 
analysis of the silt-size fraction from the same Ultisol revealed the dominant iron oxide to be oxidized magnetite (Pizarro et al. 2000a and b). Finally, results from Pizarro et al. (2008) revealed the presence of maghemite, goethite, and hematite minerals in the clay-size soil fraction from Ultisol. However, similar analysis of Andisol soil samples revealed the persistence of paramagnetic $\mathrm{Fe}^{2+}$ and $\mathrm{Fe}^{3+}$ species (the last one possibly assignable as a ferrihydrite-like mineral bonded to aluminosilicate structures) throughout all size fractions (Pizarro et al. 2000a and b; 2001; 2008). In broad terms, Andisols present higher OC content than Ultisols (Table 2). These organic compounds act similarly as inorganic anions like silicate and phosphate (Cornell and Schwertmann 2003); when bound to iron oxide surface prevent the evolution of oxides transformation into more stable, crystalline minerals thus explaining the lower crystalline degree in Andisols compared to typical Ultisol. This feature would likely influence the performance of catalysts prepared from these soil orders, since catalyzed reaction rates generally depend on the surface area (Oliveira et al. 2013) and the possible competitive effect that organic matter coatings have on catalyst active sites (DallaVilla and Nogueira 2006).

Aluminosilicate species dominant at Andisols are of rather low crystalline character if compared to those on Ultisols. It is known that poor-crystalline aluminosilicates like allophane on Andisols provide variable surface charge that depends on $\mathrm{pH}$. Aluminosilicates dominant at Ultisols provide mostly permanent negative surface charge, thus low IEP values may be expected. On the other hand, OC (Table 2) mainly provides negative surface charge at soil $\mathrm{pH}$ values. Finally, low crystalline iron oxides, like ferrihydrite, present at Andisols, provide most significant positive variable surface charge than the more crystalline iron oxides of Ultisols do. All these contributions of main soil components define, but do not permit to predict, the IEP value of a volcanic soil. This characteristic affects other surface properties such as the cation exchange capacity (CEC); thus, Andisols with higher OC content along with poor-crystalline dominant mineralogy should yield higher exchange capacity depending on the experimental $\mathrm{pH}$ (Escudey et al., 2004). Ultisols, on the other hand, exhibit lower OC and higher crystalline degree of the mineral fraction, making surface properties less influenced by the organic layer, exhibiting a low range of variability of IEP and lesser CEC than Andisols. Iron oxides are an important constituent of materials derived from volcanic ashes. Their presence has important consequences for several characteristics of these soils, such as surface charge, ion sorption rate, and magnetic properties, though the specific effect depends on the iron oxide content (expressed as $\mathrm{Fe}_{2} \mathrm{O}_{3}$ wt.\%) and types (Table 2). The proportion of distinct iron oxide types can be easily quantified through selective chemical dissolutive methods. Iron oxides may be classified as non-crystalline or free, and can be extracted using the Ammonium Oxalate (AOX) (McKeague et al. 1966) and Dithionite-Citrate-Bicarbonate (DCB) (Mehra and Jackson, 1958) chemical treatments, respectively. It is worth mentioning that for AOX method to work, the reaction should be carried out in darkness in order to dissolve amorphous iron oxides (McKeague, 1966) avoiding dissolution of $\mathrm{Fe}^{2+}$ containing crystalline minerals like magnetite. Non-crystalline iron oxides, $\mathrm{Fe}_{\mathrm{AOX}}$, represent iron oxides with low crystalline degree and are relatively in higher proportion in those soils with higher OC contents, such as Andisols. Free iron oxides in soils, $\mathrm{Fe}_{\mathrm{DCB}}$, represent amorphous and crystalline iron oxides, which cement particles within a soil sample (Mehra and Jackson, 1958). Nevertheless, it is fair to mention that chemical selective dissolutive methods are not completely selective, they rather present a preferential dissolution towards some species above others. 
Table 1. Reports for iron-bearing minerals (pure, soils, soil clay-size fractions) application on heterogeneous catalysis

\begin{tabular}{|c|c|c|c|}
\hline Catalyst & Reaction & Target & Reference \\
\hline Ferrihydrite & Catalytic oxidation & $\mathrm{Mn}(\mathrm{II})$ & Lan et al. 2017 \\
\hline $\begin{array}{l}\text { Natural olivine } \\
(\mathrm{Mg}, \mathrm{Fe})_{2} \mathrm{SiO}_{4}\end{array}$ & Bio-oil gasification & Hardwood pyrolysis bio-oil & Latifi et al. 2017 \\
\hline $\begin{array}{l}\text { Calcined nickel/olivine } \\
\left(\mathrm{Mg}_{\mathrm{x}} \mathrm{Fe}_{1-\mathrm{x}}\right)_{2} \mathrm{SiO}_{4}\end{array}$ & Methanation & $\mathrm{CO}_{2}$ & Wang et al. 2016 \\
\hline $\begin{array}{l}\text { Soil mineral and iron } \\
\text { fraction }\end{array}$ & In situ chemical oxidation & Sodium persulfate & Yu et al. 2016 \\
\hline Hematite & Photo-Fenton-like oxidation & Aqueous chlorophenylurea & Mechakra et al., 2016 \\
\hline Hematite & Photo-Fenton-like oxidation & 1-Naphtol & Mammeri et al., 2015 \\
\hline Magnetite & Fenton-like oxidation & $p$-nitrophenol & He et al., 2015 \\
\hline Natural containing Fe-clay & Fenton-like oxidation & Phenol & Djeffal et al., 2014a \\
\hline \multirow{2}{*}{ Natural containing Fe-clay } & Fenton oxidation & Phenol & Djeffal et al., 2014b \\
\hline & Photo-Fenton oxidation & Tyrosol & \\
\hline Iron-containing clays & Fenton-like oxidation & Phenol & Pham et al., 2012 \\
\hline $\mathrm{Fe}^{2+}$-containing clay & Photo-catalytic oxidation & Acetic acid & Kakuta et al., 2011 \\
\hline Ultisol sample & Fenton oxidation & Hydrogen peroxide & Manzo et al., 2011 \\
\hline Soil/charcoal composite & Fenton oxidation & Methylene-Blue & Pereira et al., 2011 \\
\hline Ultisol sample & Fenton oxidation & Hydrogen peroxide & Aravena et al., 2010 \\
\hline \multirow[t]{2}{*}{$\mathrm{H}_{2}$-reduced inceptisol } & Fenton oxidation & Hydrogen peroxide & Pereira et al., 2007 \\
\hline & & Methylene-Blue & \\
\hline Soil sample & Oxidation & Cathecol & Colarieti et al., 2006 \\
\hline Ultisol sample & WGS reaction & $\mathrm{H}_{2}$ (production) & Pizzaro et al., 2005 \\
\hline Aquifer sand & Fenton-like oxidation & Formic acid & Kwan and Voelker, 2003 \\
\hline $\begin{array}{l}\text { Sand, Road dust, Volcanic } \\
\text { ash }\end{array}$ & Photocatalytic degradation & Atrazine & Lackhoff and Niessner, 2 \\
\hline Goethite, Magnetite & Fenton-like oxidation & Petroleum & Kong et al., 1998 \\
\hline
\end{tabular}


Table 2. Properties of Chilean volcanic ash derived soils (Adapted from: Mella and Kühne 1985; Pizarro et al. 2003; Escudey et al. 2004; Pizarro et al. 2017).

\begin{tabular}{|c|c|c|c|c|c|c|c|}
\hline $\begin{array}{l}\text { Soil } \\
\text { Order* }\end{array}$ & $\begin{array}{l}\text { Al-Si dominant } \\
\text { mineralogy }\end{array}$ & $\begin{array}{l}\text { Frequently } \\
\text { Reported } \\
\text { Iron Oxides }\end{array}$ & $\mathrm{pH}$ & $\begin{array}{c}\text { OC } \\
\text { (wt.\%) }\end{array}$ & $\begin{array}{l}\text { IEP } \\
(\mathrm{pH})\end{array}$ & $\begin{array}{l}\mathrm{CEC}_{\text {Soil pH }} \\
\left(\mathrm{cmol} \mathrm{kg}^{-1}\right)\end{array}$ & $\frac{\mathrm{Fe}_{\mathrm{AOX}}}{\mathrm{Fe}_{\mathrm{DCB}}} * *$ \\
\hline Ultisol & $\begin{array}{l}\text { Halloysite } \\
\text { Kaolinite }\end{array}$ & $\begin{array}{l}\text { Magnetite } \\
\text { Maghemite } \\
\text { Goethite } \\
\text { Hematite }\end{array}$ & $4.7-5.2$ & $2.0-2.6$ & $2.6-2.9$ & $7.7-9.7$ & 0.26 \\
\hline Andisol & Allophane & $\begin{array}{l}\text { Ferrihydrite } \\
\text { Goethite } \\
\text { Magnetite } \\
\text { Ilmenite } \\
\text { Hissingerite }\end{array}$ & $4.1-6.2$ & $1.9-9.8$ & $2.7-5.3$ & $5.3-12.3$ & 0.49 \\
\hline
\end{tabular}

*According to the U.S. Soil Taxonomy 2006

** $\mathrm{Fe}_{\mathrm{AOX}}$ corresponds to non-crystalline iron oxides and can be extracted using the Ammonium Oxalate method (McKeague et al. 1966).

** $\mathrm{Fe}_{\mathrm{DCB}}$ corresponds to free iron oxides and can be extracted using the Dithionite-Citrate-Bicarbonate method (Mehra and Jackson, 1958).

Some authors have pointed out that the crystalline degree of iron oxide minerals may affect its performance as a heterogeneous catalyst. In their report on phenol degradation, Prucek et al. (2009) assumed that low-crystalline content contributed to more efficient catalytic oxidation of the target molecule. However, the authors recognised the dissolution of amorphous catalyst, resulting in homogeneous catalysis and a more efficient process compared to heterogeneous catalysis over crystalline iron oxides. Therefore, if a general relationship is to be established between the degree of iron oxide crystalline minerals in a soil and its catalytic performance, the outcomes of homogeneous and heterogeneous catalysis must be separated. Since the second is the scope of this review, we did not consider studies that detected iron leaching. Guo and Barnard (2013) on their review about naturally-occurring iron oxide nanoparticles, pointing out that low-crystalline iron oxide minerals possess large surface area to volume ratio if compared to crystalline ones, a feature that might be relevant for surface processes like adsorption and heterogeneous catalysis. On the other hand, a report by Gregor et al. (2010) demonstrated that for $\mathrm{HOOH}$ decomposition using as catalysts hematite and maghemite nanoparticles with different crystalline degrees, particles with less amorphous-phase mineral content produced higher decomposition yields; thus, crystalline degree is a more important factor, above surface area, when defining Fenton and Fenton-like catalytic processes performance. It seems that if the catalysis process is fundamentally heterogeneous, as was the case of $\mathrm{HOOH}$ decomposition, a more crystalline catalyst would improve reaction rates. To this point, the non-crystalline and the free iron oxides ratio, $\mathrm{Fe}_{\mathrm{AOX}} / \mathrm{Fe}_{\mathrm{DCB}}$, is higher in Andisols than Ultisols. However, review of available literature and experience in the field points out that 
iron oxide mineral-structure type is more important than crystalline degree in determining catalytic potential. In this regard, catalysts prepared from Ultisols should perform better as Fenton catalysts mainly due to their natural magnetite contents. This proposition will be reviewed further herein.

In summary, volcanic soils present different technological applications as heterogeneous catalysts, some of which are directly related to their iron oxide content. Despite the low-cost and ubiquity of natural iron oxides, the potential of these materials in catalytic applications may be hindered by the presence of other soil components, principally $\mathrm{OC}$ and less active mineral layers, which compete for catalytic sites and decrease efficiency. In many cases, however, pre-treatment procedures to concentrate and activate crystalline phases of iron oxides yields to improved catalysis compared to bulk soil samples, as will be discussed in more detail below. In the following sections, application of Chilean volcanic soils as catalysts for heterogeneous reactions will be reviewed as follows (1) volcanic soils as catalysts for the Water Gas Shift reaction, with special consideration of the effect of heat-treatment on the preparation of catalytic material; and (2) volcanic soils as catalysts for the Fenton reaction, with a focus on the use of physical separation (i.e. magnetic separation) and chemical concentration (i.e. $\mathrm{NaOH}$ treatment for concentration of iron-oxide crystalline minerals) methods for preparing Fenton catalysts with enhanced performance.

\section{Volcanic soils as catalysts for the water gas shift reaction}

As described by Callaghan (2006), the water gas shift reaction (WGS) is an industrial process for the conversion of $\mathrm{H}_{2} \mathrm{O}$ and $\mathrm{CO}$ into $\mathrm{H}_{2}$ and $\mathrm{CO}_{2}$ through the following reaction:

$$
\mathrm{H}_{2} \mathrm{O}+\mathrm{CO} \leftrightarrows \mathrm{H}_{2}+\mathrm{CO}_{2} \quad \Delta \mathrm{H}^{\circ}=-41.2 \mathrm{~kJ} \mathrm{~mol}^{-1}
$$

The added value of this reaction is the production of $\mathrm{H}_{2}$, a clean fuel. There is a controversy regarding the actual reaction mechanism: some authors support the theory explored by Campbell and Daube (1987) which establishes the adsorption pathway, with formate as intermediate of reaction. In contrast, other researchers support the redox route proposed by Temkin (1979). Moreover, Choi and Stenger (2003) proposed that both mechanisms occur simultaneously, to different extents, depending on the catalyst nature and working-temperature, following the reaction scheme:

$\begin{array}{rcc}\text { Adsorption mechanism } & \text { Redox mechanism } \\ \mathrm{CO}+\mathrm{Sf} \leftrightarrows \mathrm{CO} \cdot \mathrm{Sf} & (1) & \mathrm{H}_{2} \mathrm{O}+\mathrm{Sf} \leftrightarrows \mathrm{O} \cdot \mathrm{Sf}+\mathrm{H}_{2} \text { (7) } \\ \mathrm{H}_{2} \mathrm{O}+\mathrm{Sf} \leftrightarrows \mathrm{H}_{2} \mathrm{O} \cdot \mathrm{Sf} & (2) & \mathrm{O} \cdot \mathrm{Sf}+\mathrm{CO} \leftrightarrows \mathrm{CO}_{2}+\mathrm{Sf}(8) \\ \mathrm{H}_{2} \mathrm{O} \cdot \mathrm{Sf}+\mathrm{Sf} \leftrightarrows \mathrm{OH} \cdot \mathrm{Sf}+\mathrm{H} \cdot \mathrm{Sf} & \text { (3) } \\ \mathrm{CO} \cdot \mathrm{Sf}+\mathrm{OH} \cdot \mathrm{Sf} \leftrightarrows \mathrm{HCOO} \cdot \mathrm{Sf}+\mathrm{Sf} & \text { (4) } \\ \mathrm{HCOO} \cdot \mathrm{Sf} \leftrightarrows \mathrm{CO}_{2}+\mathrm{H} \cdot \mathrm{Sf} & \text { (5) } \\ 2 \mathrm{H} \cdot \mathrm{Sf} \leftrightarrows \mathrm{H}_{2} & \text { (6) }\end{array}$

The adsorption mechanism (1-6) requires a surface $(\mathrm{Sf})$ to absorb reagents and permit their reaction. The redox mechanism (7-8) capitalizes on the redox properties of the catalyst for reducing water in the first step and oxidizing carbon monoxide in the second. Since adsorption and redox properties determine the role of iron oxides in nature, natural iron oxides or soils containing a significant amount of iron oxides (such as Chilean soils derived from volcanic ashes) are logical candidates for WGS catalysis. Therefore, we reviewed the use of Chilean volcanic soils as WGS catalysts.

Our group previously studied volcanic soil samples (B-horizon) from southern Chile, specifically from Collipulli (Ultisol, 30 $54^{\circ} \mathrm{S} 72^{\circ} 25^{\prime} \mathrm{W}$ ), Osorno (Andisol, 40 33'S 73\% $4^{\circ} \mathrm{W}$ ) and San Patricio (Andisol, 38 $8^{\circ} 9^{\prime} \mathrm{S} 72^{\circ} 78^{\prime} \mathrm{W}$ ) (Escudey and Moya, 1989; Moya et al. 1991a; Pizarro et al. 2005; Pizarro et al. 2017). 
Thermal pre-treatment (heating up to $600^{\circ} \mathrm{C}$ ) of soil samples was applied for two purposes: destruction of the organic matter, which exposed active catalytic sites of iron oxides; and crystallization of the inorganic layer to alter the silicon-, aluminium- and ironoxide mineral phase. Torres-Sanchez and Tavani (1994) determined the point of zero charge (PZC) and the isoelectric point (IEP) of red soil samples after thermal shock at different temperatures, demonstrating that samples heated to $300{ }^{\circ} \mathrm{C}$ had PZC and IEP values comparable to pure iron oxide samples. This observation suggests that thermal treatment of soils samples may achieve the expected transformations (i.e. elimination of the organic matter and ordering of the iron-oxide crystalline phase) necessary for catalysis.

WGS reaction catalyst preparation from volcanic soils may in fact require the transformations brought about by heat treatment. The effect of temperature on the structure of soils has been well documented by Escudey and Moya (1989) for different Chilean volcanic soil samples. Transformations being with simple dehydration $\left(105-220^{\circ} \mathrm{C}\right)$, progress to dehydrogenation and decarboxylation of organic matter $\left(220-280^{\circ} \mathrm{C}\right)$, are followed by dehydroxylation of allophane and imogolite $\left(280-420^{\circ} \mathrm{C}\right)$, and finally reach total organic matter oxidation $\left(500^{\circ} \mathrm{C}\right)$. These expected changes have been corroborated by studies with different soil samples (Escudey and Moya 1989; Moya et al. 1991a; Pizarro et al. 2005). Table 3 presents characteristics of Chilean volcanic soils samples prior to heat treatment, including Iron, aluminium, and silicon content expressed as $\mathrm{Fe}_{2} \mathrm{O}_{3}, \mathrm{Al}_{2} \mathrm{O}_{3}$, and $\mathrm{SiO}_{2}$; OC (wt.\%); isoelectric point (IEP); and surface area as obtained by the gravimetric method based on the retention of ethylene glycol monoethyl ether (EGME).

Table 3. Soil samples parameters as function of thermal treatment temperature (Adapted from: Mella and Kühne 1985; Escudey and Moya, 1989; Moya et al. 1991; Pizarro et al. 2005)

\begin{tabular}{|c|c|c|c|c|c|c|c|c|}
\hline $\begin{array}{l}\text { Soil Sample } \\
\text { (Order) }\end{array}$ & $\begin{array}{l}\text { Series } \\
\text { Classification }\end{array}$ & $\begin{array}{c}\text { Heat Treatment } \\
\text { Temperature } \\
\left({ }^{\circ} \mathrm{C}\right)\end{array}$ & $\begin{array}{l}\mathrm{Fe}_{2} \mathrm{O}_{3} \\
\text { (wt.\%) }\end{array}$ & $\begin{array}{l}\mathrm{Al}_{2} \mathrm{O}_{3} \\
\text { (wt.\%) }\end{array}$ & $\begin{array}{c}\mathrm{SiO}_{2} \\
(\text { wt.\%) }\end{array}$ & $\begin{array}{c}\text { OC } \\
\text { (wt.\%) }\end{array}$ & IEP & $\begin{array}{c}\text { Surface Area } \\
\left(\mathrm{m}^{2} \mathrm{~g}^{-1}\right)\end{array}$ \\
\hline $\begin{array}{l}\text { Collipulli } \\
\text { (Ultisol) }\end{array}$ & $\begin{array}{l}\text { Fine, mesic, Xeric } \\
\text { Paleumult }\end{array}$ & $\begin{array}{l}124 \\
350 \\
600\end{array}$ & $\begin{array}{l}13.8 \\
14.1 \\
14.3\end{array}$ & $\begin{array}{l}19.8 \\
21.0 \\
23.6\end{array}$ & $\begin{array}{l}46.7 \\
50.0 \\
51.0\end{array}$ & $\begin{array}{l}1.5 \\
0.2 \\
0.1\end{array}$ & $\begin{array}{l}2.8 \\
2.9 \\
3.0\end{array}$ & $\begin{array}{c}155 \\
135 \\
94\end{array}$ \\
\hline $\begin{array}{l}\text { San Patricio } \\
\text { (Andisol) }\end{array}$ & $\begin{array}{l}\text { Ashy, mesic, Typic } \\
\text { Dystrandept }\end{array}$ & $\begin{array}{l}124 \\
350 \\
600\end{array}$ & $\begin{array}{c}7.3 \\
10.0 \\
10.5\end{array}$ & $\begin{array}{l}12.1 \\
18.2 \\
20.1\end{array}$ & $\begin{array}{l}35.6 \\
51.6 \\
53.6\end{array}$ & $\begin{array}{c}13.2 \\
1.6 \\
0.2\end{array}$ & $\begin{array}{l}3.2 \\
6.1 \\
6.7\end{array}$ & $\begin{array}{c}118 \\
100 \\
43\end{array}$ \\
\hline $\begin{array}{l}\text { Osorno } \\
\text { (Andisol) }\end{array}$ & $\begin{array}{l}\text { Medial, mesic, } \\
\text { Typic Dystrandept }\end{array}$ & $\begin{array}{l}124 \\
350 \\
600\end{array}$ & $\begin{array}{c}9.5 \\
11.9 \\
12.7\end{array}$ & $\begin{array}{l}17.5 \\
19.8 \\
21.3\end{array}$ & $\begin{array}{l}43.5 \\
45.4 \\
51.6\end{array}$ & $\begin{array}{l}3.7 \\
0.6 \\
0.1\end{array}$ & $\begin{array}{l}6.7 \\
6.9 \\
6.7\end{array}$ & $\begin{array}{c}142 \\
98 \\
63\end{array}$ \\
\hline
\end{tabular}


Table 3 also presents the transformations necessary for catalyst preparation from volcanic soils as a function of heating temperature. As temperature increases, OC content decreases due to calcination, while inorganic components concentrate. Almost complete destruction of $\mathrm{OC}$ is accomplished after heating to $600{ }^{\circ} \mathrm{C}$, leaving $\mathrm{Fe}-\mathrm{OH}$ active sites more exposed and producing an observable shift of the IEP values as described by Torres-Sanchez and Tavani (1994).

In the case of Collipulli soil, the potential IEP shift to higher $\mathrm{pH}$ values due to $\mathrm{Fe}-\mathrm{OH}$ exposure is compensated by exposure of more crystalline aluminosilicates as kaolinite. It is expectable that in natural soils the iron oxide surface can be coated not only by organic matter, but also by inorganic anions (e.g. silicate and phosphate), which would not be removed during heating treatment, because Chilean volcanic soils are known to fixate great amounts of such ions (Escudey et al. 2007; Redel et al. 2016). Thus, the resulting negative structural charge negates the creation of positive charge, minimizing the IEP shift. Escudey et al. (1986) proposed that the magnitude of the IEP shift depends on the acid-base dissociation constants of resulting active groups in relation to those of the original samples, as a consequence of the loss of negative charge contribution from the organic fractions and the exposure of $\mathrm{Fe}-\mathrm{OH}$ and $\mathrm{Al}-\mathrm{OH}$ active sites. Exposure of more Fe active sites may yield a better catalyst for reactions catalysed by Fe. Another parameter changed by heat treatment is surface area; its value decreases with increasing temperature, due to destruction of organic matter, water loss. XRD measurements (Escudey and Moya 1989; Moya et al. 1991b) did not showed important transformation leading to more crystalline aluminosilicates. Nevertheless, if the inorganic fraction of the untreated samples presents low crystalline iron oxide contents, crystallisation processes may take place along with surface area decrease after heating. These assumptions were recently confirmed by an elaborate study by Rzepa et al. (2016), in which thermogravimetric analyses on bog iron ores at different temperatures (up to $600{ }^{\circ} \mathrm{C}$ ) were complemented with XRD, Fourier Transform Infrared Spectroscopy (FTIR), and porous texture properties (surface area and porosity). Rzepa et al. (2016), proved that the proposed consecutive transformations (dehydration; iron oxyhydroxide dehydroxilation; oxidation of organic matter) provoke a decrease in surface area paired with disappearance of porous texture and crystallisation of iron oxides into hematite/maghemite forms. Since heat treatment yields OC destruction, exposition iron oxides, and phase-alteration of iron oxide minerals, it stands that such treatment should alter the available catalytic sites in the soil sample, thereby influencing hydrogen production through the WGS reaction. Other research groups have reported results regarding the use of iron oxide minerals or soils containing iron oxide deposits as catalysts for the WGS, but the outcomes were incidental. Publications authored by Ko (Ko et al. 2006; Ko 2008) regarding novel purification systems for coal gas consider the use of natural iron oxide containing materials (red soil and Oxisols samples). In addition to observing effective purifying capabilities through $\mathrm{H}_{2} \mathrm{~S}$ adsorption, the effluent gasmixture always contained $\mathrm{H}_{2}$ and $\mathrm{CO}_{2}$, ascribed to the WGS process. The reaction itself is typically carried out in alkaline media in moderate conditions $(0.6 \mathrm{M}$ $\mathrm{KOH}, 100{ }^{\circ} \mathrm{C}$ and $0.9 \mathrm{~atm} \mathrm{CO}$ ) using a fixed amount of catalyst (Moya et al. 1991a; Pizarro et al. 2005). Figure 1 presents hydrogen production versus time for catalysts sourced from thermally treated Chilean volcanic soil samples. 


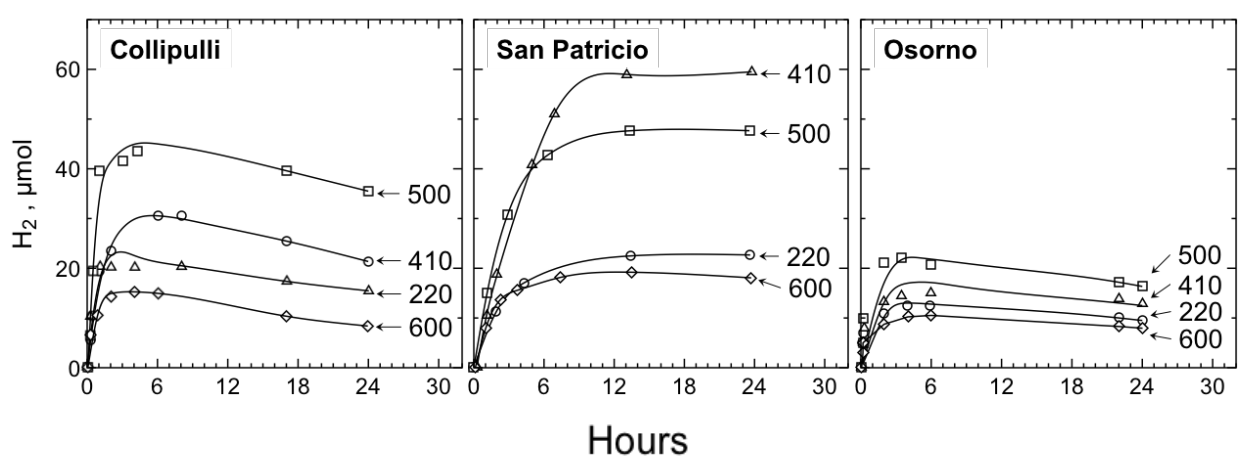

Figure 1. $\mathrm{H}_{2}$ production as function of soil and thermal treatment. Number after each curve denote thermal treatment temperatures (Adapted from: Moya et al. 1991; Pizarro et al. 2005).

Heating temperature affects catalyst performance significantly but differently for each soil. After treatment at $220^{\circ} \mathrm{C}$, all three soils produced comparable amounts of $\mathrm{H}_{2}$ (around 15-20 $\mu \mathrm{mol}$ after the first 6 hours), with Osorno being the least efficient catalyst. As pre-treatment heating temperature increases, so did $\mathrm{H}_{2}$ output in each system. Maximum performance for Collipulli and Osorno soils was achieved after pre-treatment at $500{ }^{\circ} \mathrm{C}$, while for San Patricio soils pre-treatment at $410{ }^{\circ} \mathrm{C}$ produced optimal performance with maximum production of about 60 $\mu \mathrm{mol} \mathrm{H}_{2}$ after the first 12 hours. Further increases in temperature until $600{ }^{\circ} \mathrm{C}$ generally decreased the yield for each system, which can be explained by catalyst deactivation and/or a significant reduction of specific surface area (Table 3). The authors (Moya et al. 1991a; Pizarro et al. 2005) explored further iron oxide characterisation in order to understand the catalyst transformation during the heat-treatments, employing ${ }^{57} \mathrm{Fe}$ Mössbauer Spectroscopy at room temperature in constant acceleration transmission mode with a $\sim 30 \mathrm{mCi}{ }^{57} \mathrm{Co} / \mathrm{Rh}$ source (Figure 2). soils samples and their transformation after heatingtreatment. In the spectra of untreated samples (UT), the presence of an intense central doublet indicates paramagnetic $\mathrm{Fe}^{3+}$. An incipient sextet may also be identified, which intensifies after $500{ }^{\circ} \mathrm{C}$ treatment. In this regard, and as proven by Pizarro et al. (2000a; 2000b; 2001, 2005, 2017), Ultisol soils such as Collipulli have an iron oxide mineralogy dominated by magnetite of different oxidation degrees depending on the fraction size under study. On the other hand, Andisols, younger and less evolved than Ultisols, have higher organic matter content. As Pizarro et al. (2003) demonstrated, high organic matter content hinders the crystallization processes of the mineral fraction, decreasing spectra resolution. Following pre-treatment at $500{ }^{\circ} \mathrm{C}$, signals at the ${ }^{57} \mathrm{Fe}$ Mössbauer spectra for all samples are transformed. The heat treatment should destroy the organic matter and prompt crystallisation of the inorganic fraction. These effects are supported by the $\mathrm{H}_{2}$ outcomes (Figure 1) due to the increase in production rate and by the iron oxide structure transformations observed in Figure 2. 

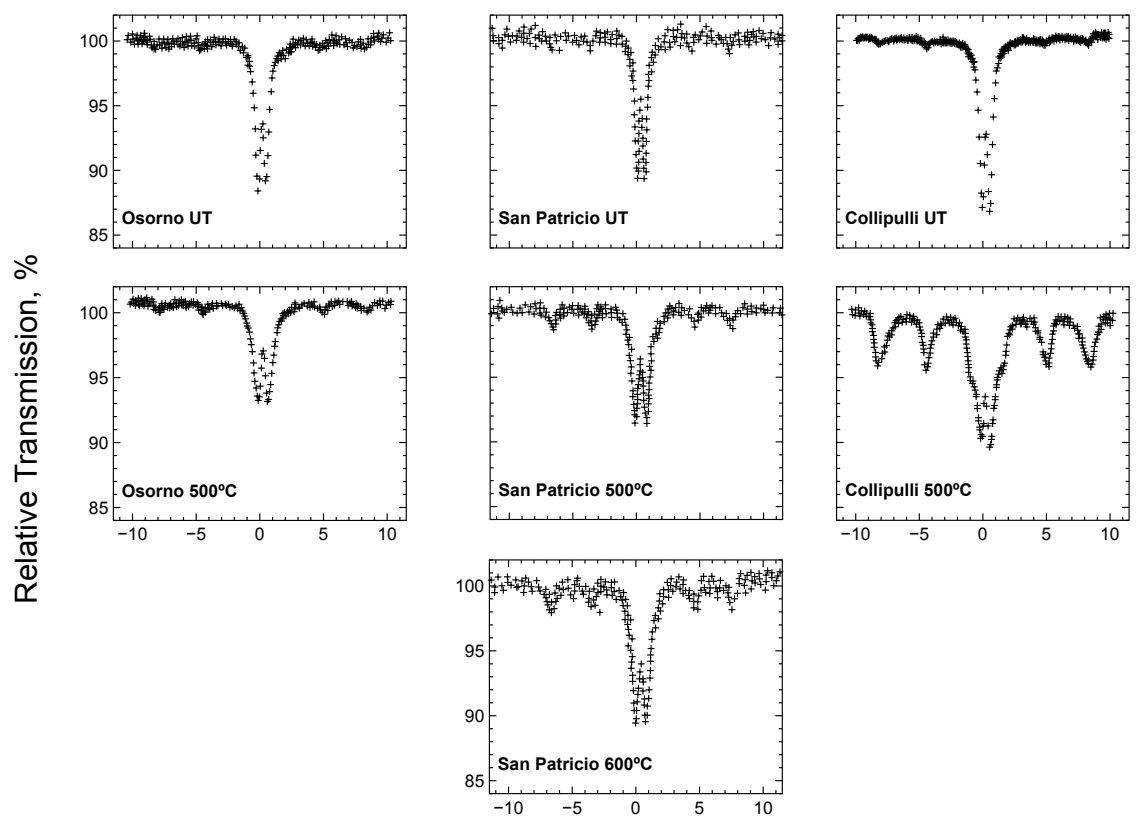

Doppler Velocity, $\mathrm{mm} \mathrm{s}^{-1}$

Figure 2. Room temperature ${ }^{57} \mathrm{Fe}$ Mössbauer spectra of untreated (UT) soils samples and after thermal treatment at the corresponding temperature. (Adapted from: Moya et al. 1991; Pizarro et al. 2005)

In this regard, the doublet in the Collipulli sample reduces its intensity and broadens, while the sextet signal seems to increase in intensity and resolution. This change represents a phase transition of the iron oxides, with an increment of the spectral proportion, with better resolved magnetically ordered components. In the case of Andisol soils, a decrease in the central doublet intensity and marginally improved resolution of the sextet are observed. These slight changes represent an increase of the $\mathrm{Fe}^{2+} / \mathrm{Fe}^{3+}$ ratio, presumably producing magnetite. Pereira et al. (2011) also produced a similar transformation when preparing an "iron oxide - charcoal" composite through a heat treatment with temperatures ranging from 400 to $800{ }^{\circ} \mathrm{C}$ on a mixture comprised of hematite-containing soil and a sucrose solution. The result was that all hematite was essentially transformed into magnetite, a finding corrobo- rated by Mössbauer analyses. The same process may occur between iron oxides from volcanic soil and their organic matter content. The oxidation of organic matter with the reduction of paramagnetic $\mathrm{Fe}^{3+}$ increases the relative proportion of the magnetically ordered structure, presumably to magnetite. Heating the samples up to $500{ }^{\circ} \mathrm{C}$ produced remarkable effects on the catalytic activity of these soils (Figure 1). Heating to $600{ }^{\circ} \mathrm{C}$ significantly reduced the catalysts' performance. Since the maximum $\mathrm{H}_{2}$ yields were observed in San Patricio soils (Figure 1), its spectra after pre-treatment at $600{ }^{\circ} \mathrm{C}$ warrant further discussion. First, as previously demonstrated in the literature (Rzepa et al. 2016), pre-treatment at 500 ${ }^{\circ} \mathrm{C}$ destroys almost all remnant organic matter. Then, at $600{ }^{\circ} \mathrm{C}$ there is essentially no additional reducing agent available in the solid. The most noteworthy change on the ${ }^{57} \mathrm{Fe}$ Mössbauer spectrum at this temperature is the in- 
crease in the central doublet (Figure 2). This indicates induction of a phase change in the iron oxide fraction, a sort of retrogression due to oxidation of $\mathrm{Fe}^{2+}$ into $\mathrm{Fe}^{3+}$, probably by the combination with $\mathrm{O}_{2}$. Moreover, as reviewed by Machala et al. (2011), depending on the medium, iron oxides tend to suffer polymorphous transformation when subjected to thermal treatments at temperatures ranging from 300 to $1300^{\circ} \mathrm{C}$. On the other hand, surface area was reduced by about $50 \%$ for all samples after pre-treatment at $600{ }^{\circ} \mathrm{C}$ (Table 3 ), representing a possible reduction in the number of available catalytic active sites. Taken together, these observations likely explain the decrease in catalyst performance at $600{ }^{\circ} \mathrm{C}$. In conclusion, volcanic soils can be used as catalysts for the WGS reaction, and heat treatment prior to application yields improved performance. The optimal heat treatment temperature may be specific to each soil type and warrants further study. As discussed above, maximum $\mathrm{H}_{2}$ yield is typically observed at an exact pre-treatment temperature. Failure to determine the optimal temperature for the soil type under study could limit resulting catalytic activity. The iron oxide content in soils undergoes transformations after each heat pre-treatment procedure. Until $500{ }^{\circ} \mathrm{C}$ the $\mathrm{Fe}^{2+} / \mathrm{Fe}^{3+}$ ratio in Andisol increases and an important increment of the magnetically ordered components in Ultisol is observed. In the $500-600^{\circ} \mathrm{C}$ range, the decrease in surface area and presumed retrogression of the iron oxide transformation might explain decreased catalytic activity. In the subsequent sections, we review the use of volcanic soils as heterogeneous catalysts for applications in environmental remediation.

\section{Volcanic soils as Fenton reaction catalysts}

The Fenton reaction involves the oxidation of organic molecules by the combined action of iron (II) and hydrogen peroxide. Several mechanisms explain the strong oxidative character of the Fenton reagent (i.e. $\mathrm{Fe}^{2+}$ combined with $\mathrm{HOOH}$ ); however, as proposed by Barbusinski (2009), the most accepted mechanism is the hydroxyl radical $(\mathrm{OH})$ pathway:

$$
\begin{aligned}
& \mathrm{Fe}^{2+}+\mathrm{HOOH} \rightarrow \mathrm{Fe}^{3+}+\mathrm{OH}^{-}+\mathrm{OH}^{-} \\
& \mathrm{OH} \cdot+\mathrm{HOOH} \rightarrow \mathrm{HO}_{2} \cdot+\mathrm{H}_{2} \mathrm{O} \\
& \mathrm{Fe}^{3+}+\mathrm{HO}_{2} \cdot \rightarrow \mathrm{Fe}^{2+}+\mathrm{H}^{+}+\mathrm{O}_{2} \\
& \mathrm{Fe}^{2+}+\mathrm{HO}_{2} \cdot \rightarrow \mathrm{Fe}^{3+}+\mathrm{HO}_{2}^{-} \\
& \mathrm{Fe}^{2+}+\mathrm{OH} \cdot \rightarrow \mathrm{Fe}^{3+}+\mathrm{OH}^{-}
\end{aligned}
$$

This mechanism consists of a chain reaction that starts with the oxidation of $\mathrm{Fe}^{2+}$ and generation of the first hydroxyl radical (9). Then the propagation steps (10 and 11) produce the hydroperoxyl radical $\left(\mathrm{HO}_{2}{ }^{\circ}\right)$ and regenerate the $\mathrm{Fe}^{2+}$. The quenching of the radical species (steps 12 and 13) represent the end of the process. The highly reactive radicals are then used for designing Advanced Oxidation Processes (AOP) with applications primarily in wastewater treatment or environmental remediation.

Natural iron oxides have been extensively studied for their catalytic application in the Fenton process. As described by He et al. (2015), the use of minerals bearing natural iron oxides presents an important advantage over synthetics. First, natural iron oxides are ubiquitous in the earth's crust, suggesting that in theory, site remediation of organic pollutants using the Fenton reaction would require only $\mathrm{HOOH}$ addition. However, as several authors have noted, the biggest limitation is that the iron mineral must contain $\mathrm{Fe}^{2+}$ in its structure or the process will not be efficient. DallaVilla and Nogueira (2006) studied organochloride pesticide degradation through the Fenton reaction in slurry systems employing polluted soil samples. Natural hematite contents within the soil did not present catalytic activity, but up to $50 \%$ pesticide degradation was achieved after soluble $\mathrm{Fe}^{2+}$ addition. Similarly, Matta et al. (2008) employed diverse natural iron oxide minerals as catalysts for Fenton degradation of trinitro- 
toluene (TNT) in aqueous suspension, demonstrating that efficiency was directly correlated to the amount of $\mathrm{Fe}^{2+}$ present at the mineral structure concentrations. In most cases, however, the iron oxide minerals are too insoluble, reducing the process speed. Therefore, many authors have proposed strategies to enhance $\mathrm{Fe}^{2+}$ availability. For instance, transformation from $\mathrm{Fe}^{3+}$ to $\mathrm{Fe}^{2+}$ has been shown to improve contaminant degradation yields in diverse systems. Pereira et al. (2007) reduced $\mathrm{Fe}^{3+}$ content in several tropical soils and in a kaolinite-mine waste sample using $\mathrm{H}_{2}$ flow. The transformed samples presented efficient Fenton degrading capabilities by Methylene-Blue (MB) decomposition in the aqueous phase. As discussed in the previous sections, the same authors (Pereira et al. 2011) produced a magnetite/charcoal composite by thermal reduction of hematite contents in soil samples with the addition of sucrose. The composite exhibited improved Fenton catalytic capacities. Another strategy is the addition of solubilisation agents to stabilise $\mathrm{Fe}^{2+}$ in solution, accelerating the Fenton reaction. Matta et al. (2008) also introduced carboxy-methyl-cyclodextrin in the iron oxide mineral suspension systems as a non-toxic iron chelant, effectively improving TNT Fenton degradation. This mechanism consists of a chain reaction that starts with the oxidation of $\mathrm{Fe}^{2+}$ and generation of the first hydroxyl radical (9). Then the propagation steps (10 and 11) produce the hydroperoxyl radical $\left(\mathrm{HO}_{2}{ }^{-}\right)$and regenerate the $\mathrm{Fe}^{2+}$. The quenching of the radical species (steps 12 and 13) represent the end of the process. The highly reactive radicals are then used for designing Advanced Oxidation Processes (AOP) with applications primarily in wastewater treatment or environmental remediation.

Natural iron oxides have been extensively studied for their catalytic application in the Fenton process. As described by He et al. (2015), the use of minerals bearing natural iron oxides presents an important advantage over synthetics. First, natural iron oxides are ubiquitous in the earth's crust, suggesting that in theory, site remediation of organic pollutants using the Fenton reaction would require only $\mathrm{HOOH}$ addition. However, as several authors have noted, the biggest limitation is that the iron mineral must contain $\mathrm{Fe}^{2+}$ in its structure or the process will not be efficient. Dalla-Villa and Nogueira (2006) studied organochloride pesticide degradation through the Fenton reaction in slurry systems employing polluted soil samples. Natural hematite contents within the soil did not present catalytic activity, but up to $50 \%$ pesticide degradation was achieved after soluble $\mathrm{Fe}^{2+}$ addition. Similarly, Matta et al. (2008) employed diverse natural iron oxide minerals as catalysts for Fenton degradation of trinitrotoluene (TNT) in aqueous suspension, demonstrating that efficiency was directly correlated to the amount of $\mathrm{Fe}^{2+}$ present at the mineral structure concentrations. In most cases, however, the iron oxide minerals are too insoluble, reducing the process speed. Therefore, many authors have proposed strategies to enhance $\mathrm{Fe}^{2+}$ availability. For instance, transformation from $\mathrm{Fe}^{3+}$ to $\mathrm{Fe}^{2+}$ has been shown to improve contaminant degradation yields in diverse systems. Pereira et al. (2007) reduced $\mathrm{Fe}^{3+}$ content in several tropical soils and in a kaolinite-mine waste sample using $\mathrm{H}_{2}$ flow. The transformed samples presented efficient Fenton degrading capabilities by Methylene-Blue (MB) decomposition in the aqueous phase. As discussed in the previous sections, the same authors (Pereira et al. 2011) produced a magnetite/ charcoal composite by thermal reduction of hematite contents in soil samples with the addition of sucrose. The composite exhibited improved Fenton catalytic capacities. Another strategy is the addition of solubilisation agents to stabilise $\mathrm{Fe}^{2+}$ in solution, accelerating the Fenton reaction. Matta et al. (2008) also introduced carboxy-methyl-cyclodextrin in the iron oxide mineral suspension systems as a non-toxic iron chelant, effectively improving TNT Fenton degradation. 
Chilean volcanic soils harbour significant amounts of iron oxide minerals, and therefore could be used directly as iron oxide-supported catalysts for the heterogeneus Fenton reaction. However, as described thoroughly in the literature, pre-treatment strategies for separation, concentration, activation, and even solubilisation of the iron oxide catalyst is required prior to direct application of bulk soils. Next, we review the most relevant results regarding the preparation of iron oxide Fenton catalysts derived from Chilean volcanic soils.

\section{Magnetic separates from Ultisol as catalysts for the Fenton reaction}

Chilean volcanic Ultisols contain a diverse array of iron oxide minerals with generally higher crystalline order compared to Andisol (Mella and Kuhne 1985; Pizarro et al. 2017) and possess different dominant iron oxide forms depending on the soil size-fraction: partially oxidised magnetite in the sand-size fraction, oxidized magnetite in the silt-size fraction, and maghemite in the clay-size fraction (Pizarro et al. 2000a, 2000b, 2001, 2005, 2017). Therefore, the sand-size fraction of Chilean Ultisols could serve as a potent catalyst for the Fenton process due to the presence of $\mathrm{Fe}^{2+}$ species in its magnetite contents.
As Pereira et al. (2007) reported, Fenton activity can be evaluated by measuring the formation of gaseous $\mathrm{O}_{2}$ from the decomposition of an exact amount of hydrogen peroxide in a volumetric gas system with controlled temperature, $\mathrm{pH}$, and a fixed amount of catalyst. The sand-size fraction of Ultisols, in which magnetite and its magnetic separates are concentrated, represents a strategic source of catalysts. Magnetic separates from natural sources have been previously studied, such as by Souza et al. (2009), who employed the magnetic fraction of pulverized limonite samples for Fenton decomposition of quinoline in the aqueous phase. Application of magnetic separates concentrated from maghemite mineral increased reaction rate. In Chilean volcanic soil samples, magnetic separation is a feasible procedure achieved by suspending the sand-size soil fraction in water and isolating the magnetic particles with a hand-held magnet. Then, the specific magnetization of soils is measured with a portable soil magnetometer. The general characteristics of the sand-size soil fraction and their magnetic separates for two Chilean Ultisols, Collipulli (30 $54^{\circ} \mathrm{S} 72^{\circ} 25^{\prime} \mathrm{W}$ ) and Metrenco (38 $34^{\prime} \mathrm{S}$ $72^{\circ} 22^{\prime} \mathrm{W}$, see location at Pizarro et al. 2017), are summarized in Table 4 (Aravena et al. 2010).

Table 4. Chemical composition (expressed as oxides) of Ultisols sand samples and their magnetic separates. (Adapted from Aravena et al. 2010).

\begin{tabular}{|c|c|c|c|c|c|c|c|}
\hline Sample & $\begin{array}{l}\text { Series } \\
\text { Classification }\end{array}$ & $\begin{array}{l}\text { Al-Si dominant } \\
\text { mineralogy }\end{array}$ & Fraction & $\begin{array}{l}\mathrm{Fe}_{2} \mathrm{O}_{3} \\
\text { (wt.\%) }\end{array}$ & $\begin{array}{c}\mathrm{Si}_{2} \mathrm{O} \\
(w t . \%)\end{array}$ & $\begin{array}{l}\mathrm{Al}_{2} \mathrm{O}_{3} \\
\text { (wt.\%) }\end{array}$ & $\begin{array}{c}\mathrm{TiO}_{2} \\
\text { (wt.\%) }\end{array}$ \\
\hline Collipulli & $\begin{array}{l}\text { Fine, mesic, Xeric } \\
\text { Paleumult }\end{array}$ & Halloisite & $\begin{array}{l}\text { Sand } \\
\text { Mag- separates }\end{array}$ & $\begin{array}{l}14.6 \\
56.7\end{array}$ & $\begin{array}{c}43.2 \\
\text { nd }\end{array}$ & $\begin{array}{c}23.1 \\
\text { nd }\end{array}$ & $\begin{array}{l}2.0 \\
3.6\end{array}$ \\
\hline Metrenco & $\begin{array}{l}\text { Fine, mesic, } \\
\text { Paleumult }\end{array}$ & Kaolinite & $\begin{array}{l}\text { Sand } \\
\text { Mag-separates }\end{array}$ & $\begin{array}{l}16.9 \\
57.0\end{array}$ & $\begin{array}{c}51.9 \\
\text { nd }\end{array}$ & $\begin{array}{c}19.0 \\
\text { nd }\end{array}$ & $\begin{array}{l}2.4 \\
3.1\end{array}$ \\
\hline
\end{tabular}

nd: not determined 
Comparison of the amount of iron and the magnetic separates for each soil reveals that separation is the right strategy to achieve the effective magnetite concentration. Total iron, manganese and titanium contents, expressed as $\mathrm{Fe}_{2} \mathrm{O}_{3}, \mathrm{TiO}_{2}$ and $\mathrm{MnO}_{2}$ wt.\%, increase with magnetic separation. As demonstrated by Pizarro et al. (2001), it is likely that, on magnetic separates, the main iron oxide mineral corresponds to $\mathrm{Fe}_{3} \mathrm{O}_{4}$ with magnesium and titanium replacing ferrous ion $\mathrm{Fe}_{2+}$ in the magnetite presents in Ultisols.

Fenton activity can be evaluated through quantification of $\mathrm{HOOH}$ decomposition via $\mathrm{O}_{2}$ volume measurement on a gas-tight system $\left(3.5 \mathrm{~mol} \mathrm{~L}^{-1}\right.$ hydrogen peroxide on a volumetric gas system at $\mathrm{pH} 5.0$ at $21{ }^{\circ} \mathrm{C}$ using $15 \mathrm{mg}$ of the respective catalyst) as described by Aravena et al. (2010). In this work the decomposition kinetics of $\mathrm{HOOH}$ appeared to be of pseudo zeroth order regardless of the catalyst type. The reaction rate constant for $\mathrm{HOOH}$ decomposition when employing Collipulli and Metrenco magnetic separates were $40.0 \times 10^{-5}$ and $8.0 \times 10^{-5} \mathrm{M} \mathrm{min}^{-1}$, respectively. Decomposition of $\mathrm{HOOH}$ is comparatively faster when using magnetic separates from Collipulli versus Metrenco samples. As mentioned, the differences in catalytic performance might be explained by the quality of their iron oxide contents. Further characterisation of iron oxide structures by ${ }^{57} \mathrm{Fe}$ Mössbauer spectroscopy of their magnetic separates is presented in Figure 3 (Adapted from Aravena et al. 2010).
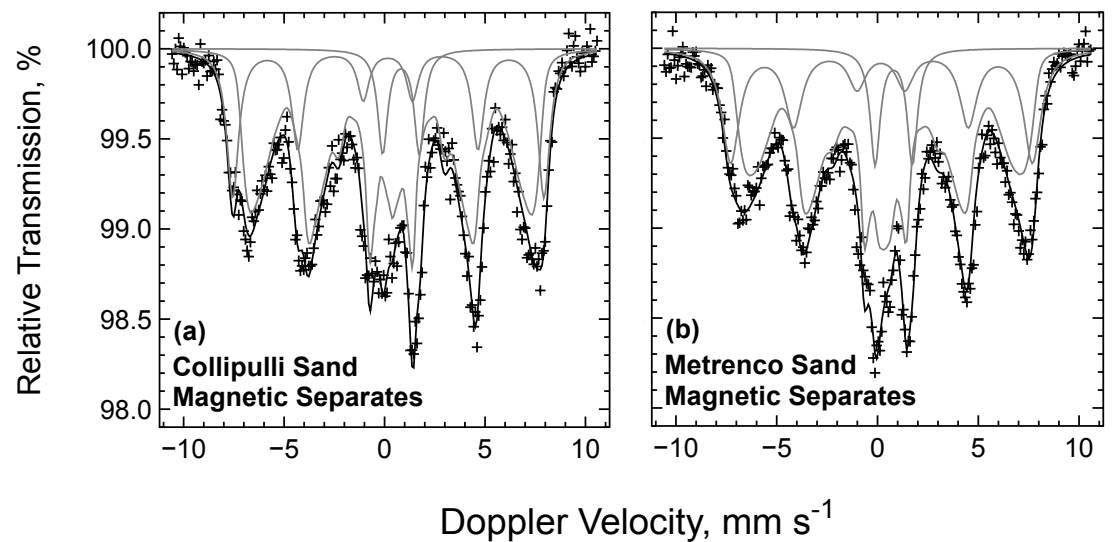

Figure 3. Room Temperature ${ }^{57} \mathrm{Fe}-\mathrm{Möss} b a u e r$ spectra for the magnetic separates from (a) Collipulli and (b) Metrenco sand-size soil samples, respectively. (Adapted from Aravena et al. 2010) 
As Pizarro et al. (2000a and b) reports, Ultisol iron oxide mineralogy can be successfully described by analysing soil magnetic separates (Figure 3). From spectra for both samples, a simultaneous quadrupolar and magnetic unfolding can be observed. In each case, magnetic unfolding consists of six lines, but the four interiors are displaced with respect to the externals. This combined effect is usually seen on natural-origin magnetic materials where iron atoms are occupying sites with an ideal cubic symmetry. The hyperfine parameters obtained after model fitting reveal that nonstoichiometric magnetite is the main iron oxide present for the magnetic separates.

Hyperfine parameters for room temperature Mössbauer spectrum of Collipulli magnetic separates (Figure 3 a) indicate that there is a non-stoichiometric magnetite block with an isomeric shift $\delta=0.28 \mathrm{~mm} \mathrm{~s}^{-1}$; a quadrupole splitting $\varepsilon=0.02 \mathrm{~mm} \mathrm{~s}^{-1}$; and a hyperfine field $\mathrm{B}_{\mathrm{hf}}=48.0 \mathrm{~T}$. These values are characteristic of the tetrahedral sites of magnetite, representing $24 \%$ of the whole spectral area, RA. Observation of a second distribution block is due to the presence of mixed valence $\mathrm{Fe}^{2+}$ and $\mathrm{Fe}^{3+}$ species at the octahedral sites of a partially oxidised magnetite with a broad $\mathrm{B}_{\mathrm{hf}}$ distribution between 28.3 and $44.6 \mathrm{~T}$, representing about the $69 \%$ RA. In the case of the Metrenco magnetic separates Mössbauer spectrum (Figure 3 b), hyperfine parameters obtained after model fitting reveal the presence of a non-stoichiometric magnetite block with $\delta 0.29 \mathrm{~mm} \mathrm{~s}^{-1}, \varepsilon 0.03 \mathrm{~mm} \mathrm{~s}^{-1}$, and $\mathrm{B}_{\mathrm{hf}} 46.4 \mathrm{~T}$, values characteristic of the octahedral sites of magnetite, representing a $26 \%$ RA. As seen for Collipulli, there is a distribution block due to the presence of mixed valence $\mathrm{Fe}^{2+}$ and $\mathrm{Fe}^{3+}$ species at the octahedral sites of a partially oxidised magnetite with a broad Bhf between 27.8 and $45.2 \mathrm{~T}$, representing a $68 \%$ RA. The rest of the spectra for both magnetic separate samples is explained by the presence of small central doublet subspectrum consisting of paramagnetic $\mathrm{Fe}^{3+}$ species with a $\delta$ of 0.92 and $0.91 \mathrm{~mm} \mathrm{~s}^{-1}$ for Collipulli and Metrenco, respectively. These results show that there is no clear difference between Ultisol samples with respect to iron oxide mineralogy based on interpretation of the Mössbauer spectra of their magnetic separates. Therefore, the catalytic performances of these materials cannot be determined solely by means of Mössbauer spectroscopy. On the other hand, XRD analyses of the magnetic separates revealed the presence of magnetite with isomorphic substitution of $\mathrm{Ti}$ (Pizarro et al. 2001, and authors' unpublished data) among other compounds (Table 4). Taken together, this characterisation may explain the differences in catalytic performance observed for both Ultisols. The difference observed, however, is that titanium content on Collipulli magnetic separates is higher than on Metrenco (Table 4), conforming, presumably, titanomagnetite structures as has been confirmed for Collipulli samples (Pizarro et al. 2001). Zhong et al. (2012) demonstrated that increasing Ti proportions, fixated on magnetite-based catalysts, greatly enhances the photo-Fenton degradation of tetrabromobisphenol. Thus, the Ti content of Collipulli, at least in part, explain its superior performance as Fenton catalyst. Also, both soils have different dominant aluminosilicate mineralogy (Table 4), with halloysite and kaolinite for Collipulli and Metrenco, respectively. More than just the product of their distinct geological origin, this key difference likely produces distinct geometrical surface area on exposed iron oxide catalytic sites. A similar conclusion may be drawn from the results of He et al. (2015), which pertain to the use of natural Chinese magnetite from different sources as a Fenton catalyst for p-nitrophenol decomposition. The authors reported that after crushing and grinding mineral samples, magnetite was hand-picked under a binocular microscope followed by magnetic separation. Despite the meticulous methodology used to ensure isolation of pure natural magnetite, some intrinsic 
phase impurities (i.e. exsolved lamellae ilmenite, neoplaste) were observed, as well as recurrent isomorphic substitution of Fe by other transition metals. These limitations significantly affected the catalytic performance of the magnetite minerals. Therefore, advances in the strategies to concentrate catalytically active iron oxide minerals from volcanic ash-derived soil samples should improve the catalytic performance of these natural-origin materials.

\section{$\mathrm{NaOH}$ treatment of volcanic soil samples for en- hancement of catalytic performance in the Fenton process}

The catalytic potential of iron oxides in volcanic soils may be hindered by the presence of other components in soils such as organic matter, $\mathrm{Al}$, or $\mathrm{Al} / \mathrm{Si}$ minerals. Their effect may involve blocking the catalytic sites of iron oxides, which would reduce the active surface available for reaction. Pre-treatment methods such as selective chemical dissolution could improve the catalytic potential of iron oxide minerals obtained from volcanic soils. As first reported by Norrish and Taylor (1961), washing with concentrated $\mathrm{NaOH}$ solution concentrated iron oxides in the solid phase of soils, selectively dissolving aluminium oxides and aluminosilicate species. Therefore, this method could be used to concentrate iron oxides from the silt+clay fractions of Chilean volcanic soils. Moreover, since $\mathrm{NaOH}$ treatment preferentially removes aluminium oxide, and aluminosilicates, the final product should demonstrate improved catalytic capabilities. Pham et al. (2012) employed the DCB method to remove free iron and magnesium oxides from an "iron-containing clay" (formed mainly by montmorillonite) when studying phenol decomposition through the Fenton process. While DCB treated samples presented slower reaction rates for $\mathrm{HOOH}$ decomposition, phenol degradation was more stoichiometric efficient, defined as the amount of phenol transformed per mole of $\mathrm{HOOH}$ decomposed.

Theoretically, any volcanic ash derived soil should be a good candidate as raw material to be prepared as Fenton and Fenton-like catalyst, especially those with minerals containing natural $\mathrm{Fe}^{2+}$ structures (Pizarro et al. 2017). Manzo et al. (2011) selected the silt+clay fraction of Collipulli (Ultisol, 30 $34^{\circ}$ 'S $72^{\circ} 25^{\prime} \mathrm{W}$ ) to study its performance as Fenton catalysts. As reported, silicates and aluminosilicates in this fraction may be removed by extractions of concentrated heated $\mathrm{NaOH}$ (i.e., $5 \mathrm{M}$ and $90{ }^{\circ} \mathrm{C}$ for 1 hour; Manzo et al. 2011). The number of $\mathrm{NaOH}$ washes was optimised as a function of their performance as catalyst for the Fenton reaction. Iron oxide contents at the silt+clay samples (expressed as $\mathrm{Fe}_{2} \mathrm{O}_{3}$ wt.\%) shifted from 12.2 to 25.1 after $3 \mathrm{NaOH}$ washes and to 23.3 after five washes; thus, concentration of iron oxides at the solid phase was effective, almost doubling their contents after 3 subsequent $\mathrm{NaOH}$ treatments. After alkali treatments, the silt+clay samples were tested as catalysts for the $\mathrm{HOOH}$ decomposition. The reactions followed pseudo-zeroth order kinetics; after the alkali treatments rate constants were $16.0 \times 10^{-5}$ and $7.1 \times 10^{-5} \mathrm{M}$ $\mathrm{min}^{-1}$ for Collipulli silt+clay catalyst prepared with 3 and $5 \mathrm{NaOH}$ washes, respectively. Then, it seems that $3 \mathrm{NaOH}$ treatments optimise the peroxide decomposition rate while five consecutive $\mathrm{NaOH}$ washes seemed to reduce the catalyst efficiency.

Alkali treatments modify silicon and aluminium contents in Collipulli silt+clay fraction. With respect to silicon content (expressed as $\mathrm{SiO}_{2}$ wt.\%), it decreases from 41.1 for the untreated soil samples (silt+clay) to 15.8 and finally to 10.5 after 3 and $5 \mathrm{NaOH}$ washsteps, partially dissolving silicate minerals. Similarly, Pizarro et al. (2000b) observed a decrease on XRD quartz signal after subjecting silt size soil samples to $\mathrm{NaOH}$ washes. However, aluminium (expressed as $\mathrm{Al}_{2} \mathrm{O}_{3}$ wt.\%) behave differently, since the untreated 
soil samples (silt+clay) contents of 26.5 decreased to 9.0 after $3 \mathrm{NaOH}$ treatments but then increased to 12.1 after the fifth, attributed to aluminium re-precipitation process over the solid particles (Manzo et al. 2011). Kwan and Voelker (2003) also proposed that, when studying formic acid decomposition through the Fenton reaction employing different catalyst materials such as synthetic iron oxides and an iron-oxide coated quartzitic aquifer sand. The presence of impurities on natural-origin catalysts interferes with the process, hindering the possibility of predicting reaction rates. Usage of $\mathrm{NaOH}$ has been reported to improve Fenton reaction performance for different catalysts. Chen et al. (2014) presented the preparation of different Fetitanates employing the alkali-hydrothermal approach (10 M NaOH and $80{ }^{\circ} \mathrm{C}$ for $24 \mathrm{~h}$ ), a method with similar conditions as the $\mathrm{NaOH}$ washes reported by Manzo et al. (2011), obtaining Fe-titanates with isomorphic $\mathrm{Na}^{+}$substitutions that displayed decolourization efficiencies as high as $80 \%$ for rhodamine $6 \mathrm{G}$ dye. Recently, Roy and Naskar (2016) published an article presenting the preparation of a Fenton catalyst consisting on hematite microparticles with isomorphic substitutions of alkali metals $\left(\mathrm{K}^{+}, \mathrm{Li}^{+}\right.$and $\left.\mathrm{Na}^{+}\right)$ and observed that sodium incorporation into hematite structures enhanced magnetic properties and degrading efficiencies of colorant methylene blue up until $90 \%$. Therefore, from bibliographic revision, it seems that besides removal of silicates and aluminosilicates, $\mathrm{Na}^{+}$incorporation within iron oxide structures of Fenton catalyst somehow enhances its degrading capacities, which may be the case for catalyst prepared with volcanic ashes derived materials Therefore, considering the $\mathrm{NaOH}$ treatments influence over the catalyst performance, Collipulli silt+clay soil samples seems to show promising results. Nevertheless, if reaction rate constant for the $\mathrm{HOOH}$ decomposition reaction with Collipulli silt+clay $3 \mathrm{NaOH}\left(16.0 \times 10^{-5} \mathrm{M} \mathrm{min}^{-1}\right)$ is compared with that obtained from Collipulli magnetic separates from the sandy fraction $\left(40.0 \times 10^{5} \mathrm{M} \mathrm{min}^{-1}\right)$, the former works ca. 3 times faster, meaning that the Ultisol magnetic separates offer more active surfaces for the Fenton process. This comparison was corroborated after analysing the iron oxide mineralogy of the catalysts following $\mathrm{NaOH}$ treatment. To accomplish this, $80 \mathrm{~K}{ }^{57} \mathrm{Fe}$ Mössbauer spectra for Collipulli silt-size, clay-size and silt+clay-size fraction after 3 $\mathrm{NaOH}$ treatments are presented on Figure 4 (Adapted from Pizarro et al. 2008 and Manzo et al. 2011).

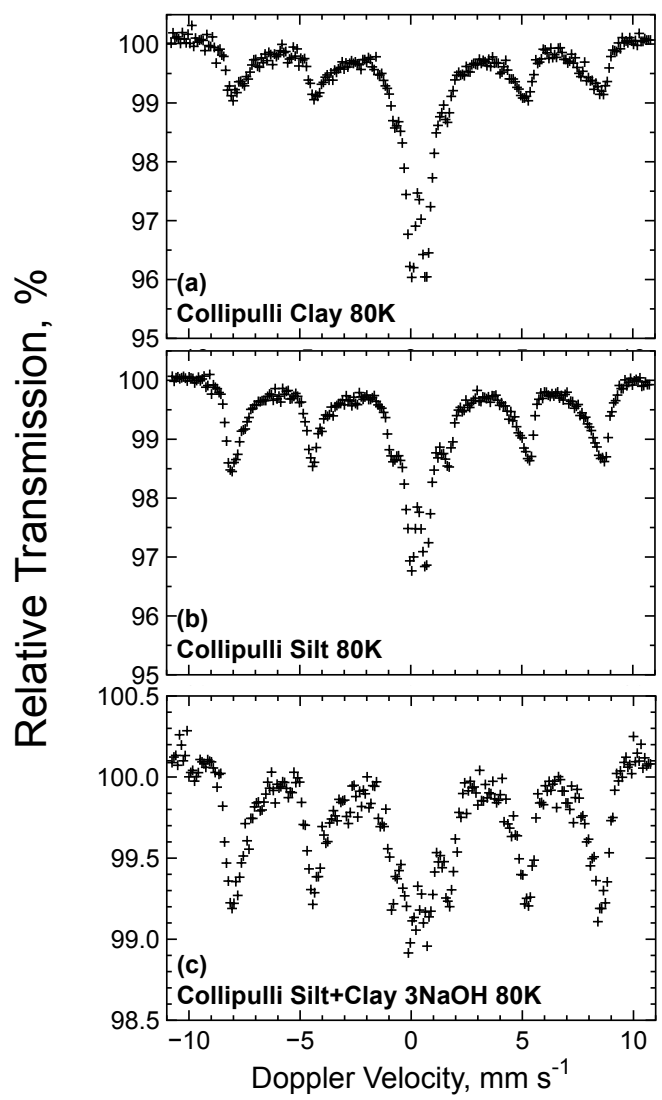

Figure 4. Mössbauer spectra at $80 \mathrm{~K}$ for Collipulli untreated silt (a) and clay-size (c) fractions and silt+clay size fraction after $3 \mathrm{NaOH}$ treatments (c). (Adapted from Pizarro et al. 2008 and Manzo et al. 2011) 
Figure 4 displays $80 \mathrm{~K}{ }^{57} \mathrm{Fe}$ Mössbauer measurement on Collipulli samples (silt, clay without $\mathrm{NaOH}$ washes and silt+clay samples after $3 \mathrm{NaOH}$ treatments) in order to show size-fraction separation and $\mathrm{NaOH}$ treatments effects on the qualitative description of iron oxide minerals present at volcanic soils. For the untreated silt and clay-size fractions, Figure 4 (a) and (b), shape and positions of signals is typical for complex mineral assemblages. This situation in volcanic soils, is characterised by an intense central doublet due to (super)paramagnetic $\mathrm{Fe}^{3+}$ presumed to belong to a ferrihydrite-like mineral, and a broad sextet typical of several closely coexisting magnetically ordered forms of iron oxides. As reported by Manzo et al. (2011) the $80 \mathrm{~K}$ Mössbauer spectrum of Collipulli silt+clay after $3 \mathrm{NaOH}$ treatments shows that the resonance signals are significantly more intense that those obtained with the untreated silt and clay fractions (Figure $4 \mathrm{c}$ ). This means that alkali treatments are enough to increase the concentration of iron oxides in the solid phases of this geomaterial. According as Pizarro et al. (2017) silt and clay size fractions of Collipulli contain oxidized magnetite, maghemite and hematite (intrinsically bonded to the aluminosilicates) as Fenton and Fenton-like active iron oxide minerals. Despite not containing $\mathrm{Fe}^{2+}$, maghemite and hematite have been found to show catalytical activity if some conditions are met. Ferroudj et al. (2013) reported that maghemite nanoparticles showed good activity towards Fenton degradation of water pollutants. Also, on its review, Pereira et al. (2012) explained that when hematite is bonded to an aluminosilicate structure, the $\mathrm{Al} / \mathrm{Si}$ compound may act as a Lewis acid, attracting the electron cloud from $\mathrm{Fe}^{3+}$. This would facilitate a reduction-like process in the presence of $\mathrm{HOOH}$, producing $\mathrm{Fe}^{2+}$, the actual active Fenton species. In line with this idea, Lim et al. (2006) prepared Fenton catalyst from hematite supported on aluminacoated mesoporous silica, achieving good catalytic performance. Additionally, Botas et al. (2010) reported synthesis of Fenton catalysts by the deposition of crystalline hematite over mesostructured and amorphous silica powders, showing good heterogeneous catalysis performance during phenol decomposition. Therefore, the amounts of oxidized magnetite and hematite contents (bonded to aluminosilicates) present in Collipulli $3 \mathrm{NaOH}$ catalysts explains its Fenton performance. Some authors have suggested that in certain cases Fenton conditions may solubilize $\mathrm{Fe}^{2+}$ into solution, which provokes homogeneous Fenton reaction (Lu et al. 2002) on an accelerated rate. This was not the situation reported by Manzo et al. (2011) since no more than $0.02 \mathrm{mg} \mathrm{L}^{-1}$ of soluble iron was quantified during catalysis assays. In addition, Pereira et al. (2007) have found that iron leachates as concentrated as $0.08 \mathrm{mg} \mathrm{L}^{-1}$, from experiments with similar conditions as those revised (Manzo et al. 2011), may provoke less than $0.1 \%$ of homogeneous Fenton reaction, thus proving that this process occurs mainly in heterogeneous phase.

The differences observed in reaction rate constants for $\mathrm{HOOH}$ decomposition by the sand-size fraction magnetic separates of Collipulli vs Collipulli-3- $\mathrm{NaOH}$ treatments $\left(40.0 \times 10^{-5}\right.$ and $15.0 \times 10^{-5} \mathrm{M} \mathrm{min}^{-1}$, respectively) may be explained by superior separation of Fenton-active minerals through magnetic concentration compared to the $\mathrm{NaOH}$ selective dissolutive method. In addition, Ultisols have distinct dominant iron oxide mineralogy in their respective size fractions (Pizarro et al. 2017). In contrast, magnetic separates from the Collipulli sand-size fraction contain iron oxides dominated by magnetite (Figure 3), one of the most efficient and well-studied iron oxide minerals in Fenton catalysis applications (Pereira et al., 2012). Moreover, as demonstrated by Yang et al. (2009) and Zhong et al. (2012) magnetite with isomorphic replacement of $\mathrm{Fe}$ by $\mathrm{Ti}$ atoms, as it was established after the X-ray diffraction analyses for the 
Ultisols magnetic separates (Pizarro et al. 2001), is known to produce significant improvement regarding the Fenton process efficiency. On the case of Collipulli $3 \mathrm{NaOH}$, as it was recently mentioned, oxidized magnetite contents, along with its hematite contents may account for their performance as Fenton and Fenton-like catalyst, not comparable, though, to the performance of Collipulli sand-size fraction magnetic separates, which performs 3 times faster for $\mathrm{HOOH}$ decomposition. In summary, volcanic soils can be used as sources of heterogeneous catalysts for the Fenton process. Their performance can be modulated as function of physical separation (magnetic separates) and/ or selective dissolutive chemical treatments such as concentrated $\mathrm{NaOH}$ washes for iron oxide concentration. The number of $\mathrm{NaOH}$ treatments warrants careful consideration to optimise reaction rates during the Fenton process. Results regarding Collipulli samples reviewed herein show that 3 consecutive $\mathrm{NaOH}$ treatments yielded better catalyst efficiency for the Fenton process, with Collipulli $3 \mathrm{NaOH}$ (Ultisol) being superior to other $\mathrm{NaOH}$ treated samples. Still, the activity of Collipulli $3 \mathrm{NaOH}$ was not comparable to that of magnetic separates from the Collipulli sand-size soil fraction. Mössbauer characterisation of the catalyst during modification revealed that $\mathrm{NaOH}$ treatments of Collipulli samples concentrated the Fenton-active iron oxides layers, as aluminosilicate-bonded hematite, maghemite, titanomagnetite and magnetite to be major constituents.

The real technical potentiality of these alternative catalysts from natural sources must not only consider their catalytic performance but also the complexity on the preparation processes and the final cost compared with the catalysts usually used for the type of reactions evaluated in this review. Conventional heterogeneous catalysts costs involve the expenses associated to the support-selection, catalyst synthesis, purification and activation steps. An advantage of using natural-origin catalyst, as has been proved on this review, is that they only require simple and non-expensive activation steps to be ready to use.

\section{Conclusions}

Soils derived from volcanic ashes are natural sources of iron oxides and offer potential technological applications in the field of heterogeneous catalysis. The water gas shift and the Fenton reaction were studied using catalysts prepared from volcanic soils. After thermal treatment of soil samples, Andisols functioned more efficiently than Ultisols for the watergas-shift reaction. From mineralogical characterisation, it seems that water-gas-shift reaction efficiency depends on phase shift and the $\mathrm{Fe}^{2+} / \mathrm{Fe}^{3+}$ ratio changes produced through heating. In the case of the Fenton processes, catalysis performance was enhanced by physical and chemical treatments applied to different size fractions of Ultisol samples. Magnetic separation from the Ultisol sand-size soil fraction showed the best catalytic performance as a Fenton reagent due to its natural magnetite and titanomagnetite content. $\mathrm{NaOH}$ treatments were used to concentrate the crystalline iron oxide contents from the silt+clay size fraction of volcanic soils, producing a Fenton catalyst with improved performance. After characterisation, it was revealed that Ultisol silt+clay size fraction after $3 \mathrm{NaOH}$ consecutive treatments possessed magnetite and aluminosilicate-bonded hematite as most active Fenton minerals $(\mathrm{HOOH}$ decomposition rate of $\left.16 \times 10^{-5} \mathrm{M} \mathrm{min}^{-1}\right)$. If this performance is compared, however, with that of Ultisol magnetic separates from sand-size soil fraction $(\mathrm{HOOH}$ decomposition rate $40.0 \times 10^{-5} \mathrm{M} \mathrm{min}^{-1}$ ) the second were a more efficient source of catalyst material, explained by its magnetite and titanomagnetite reported contents. Therefore, thermal treatment along with physical separation and selective chemical dissolution methods represent 
promising strategies to improve the catalytic capabilities of iron oxides from volcanic soils.

\section{Acknowledgements}

This work was supported by Proyecto Dicyt-USACH 021742PA, Proyecto Basal USA1555 USACH, Proyecto Fortalecimiento USACH USA1799 PC272512, CONICYT PIA/ACM170002 and CEDENNA FB-0807 (Chile). The authors thank the Brazilian National Council for the Scientific and Technological Development (CNPq) for stimulating their international scientific collaboration in Latin America, under the grant \# PROSUL 490096/2010-7. JDF is also indebted to the Minas Gerais State Foundation for the Support of Science and Technology (FAPEMIG, Brazil; grant \# CEX PPM 00412-15), to CNPq (grant \# 305755/2013-7) for continuously supporting his research activities and to CAPES (Brazil) for granting his Visiting Professorship at UFVJM under the PVNS program.

\section{References}

Aravena, S., Pizarro, C., Rubio, M.A., Cavalcante, L.C.D., Garg, V.K., Pereira, M.C., Fabris, J.D. 2010. Magnetic minerals from volcanic Ultisols as heterogeneous Fenton catalysts. Hyperfine Interact. 195, 35-41.

Barbusinski, K. 2009. Fenton reaction - Controversy concerning the chemistry. Eco. Chem. Eng. Sci. $16,347-358$.

Botas, J.A., Melero, J.A., Martinez, F., Pariente, M.I. 2010. Assessment of $\mathrm{Fe}_{2} \mathrm{O}_{3} / \mathrm{SiO}_{2}$ catalysts for the continuous treatment of phenol aqueous solutions in a fixed bed reactor. Catal. Today 149, 334-340.

Braunschweig, J., Bosch, J., Meckenstock, R.U. 2013. Iron oxide nanoparticles in geomicrobiology: from biogeochemistry to bioremediation. New Biotechnol. 30, 793-802.

Calabi-Floody, M., Theng, B.K.G., Reyes, P., Mora, M.L. 2009. Natural nanoclays: application and future trends - a Chilean perspective. Clay Miner. 44, 161-176.

Calabi-Floody, M., Rumpel, C., Velasquez, G., Violante A., Bol, R., Condron, L.M., Mora, M.L. 2015. Role of nanoclays in carbon stabilization in Andisols and Cambisols. J. Soil Sci. Plant Nutr. $15,587-604$.

Callaghan, C.A. 2006. Kinetics and Catalysis of the Water-Gas-Shift Reaction: A Microkinetic and Graph Theoretic Approach, in: A Dissertation Submitted to the Faculty of the Worcester Polytechnic Institute Department of Chemical Engineering.

Campbell, C.T. and Daube, K.A. 1987. A surface science investigation of the water-gas shift reacton on copper (111). J. Catal. 104, 109-119.

Chen, Y., Li, N., Zhang, Y., Zhang, L. 2014. Novel low-cost Fenton-like layered Fe-titanate catalyst: Preparation, characterization and application for degradation of organic colorants. J. Colloid Interface Sci. 422, 9-15.

Choi, Y., Stenger, H.G. 2003. Water gas shift reaction kinetics and reactor modeling for fuel cell grade hydrogen. J. Power Sources 124, 432-439.

Colarieti, M.L., Toscano, G., Ardi, M.R., Greco Jr, G. 2006. Abiotic oxidation of catechol by soil metal oxides. J. Hazard. Mater. B134, 161-168.

Cornell, R.M., Schwertmann U. 2003. The Iron Oxides. WILEY-VCH Verlag GmbH \& Co. KGaA, Weinheim.

Dalla-Villa, R. and Nogueira, R.F.P. 2006. Oxidation of p,p'- DDT and p,p'-DDE in highly and longterm contaminated soil using Fenton reaction in a slurry system. Sci. Total Environ. 371, 11-18. 
de Smit, E. and Weckhuysen, B.M. 2008. The renaissance of iron-based Fischer-Tropsch synthesis: on the multifaceted catalyst deactivation behaviour. Chem. Soc. Rev. 37, 2758-2781.

Djeffal, L., Abderrahmane, S., Benzina, M., Fourmentin, M., Siffert, S., Fourmentin, S. 2014a. Efficient degradation of phenol using natural clay as heterogeneous Fenton-like catalyst. Environ. Sci. Pollut. Res. 21, 3331-3338.

Djeffal, L., Abderrahmane, S., Benzina, M., Fourmentin, M., Siffert, S., Fourmentin, S. 2014b. Efficiency of natural clay as heterogeneous Fenton and photo-Fenton catalyst for phenol and tyrosol degradation. Desalin. Water Treat. 52, 2225-2230.

Escudey, M., Galindo, G., Ervin, J. 1986. Effect of iron oxide dissolution treatment on the isoelectric point of allophanic soils. Clay. Clay Miner. 34, 108-110.

Escudey, M. and Moya, S.A. 1989. Use of volcanicash-derived aoil as iron oxide supported catalysts. Colloid. Surface. 37, 141-148.

Escudey, M., Förster, J. E. Galindo, G. 2004. Relevance of organic matter in some chemical and physical characteristics of ash-derived soils. Commun. Soil Sci. Plant Anal. 35, 781-797.

Escudey, M., Galindo, G., Förster, J.E., Briceño, M., Diaz, P., Chang, A. 2007. Chemical forms of phosphorus of volcanic ash-derived soils in Chile. Commun. Soil Sci. Plant Anal. 32, 601- 616.

Ferroudj, N., Nzimoto, J., Davidson, A., Talbot, D., Briot, E., Dupuis, V., Béea, A., Medjram, S., Abramsona, S. 2013. Maghemite nanoparticles and maghemite/silica nanocomposite microspheres as magnetic Fenton catalysts for the removal of water pollutants. Appl. Catal. B Environ. 136-137, 9-18.

Filip, J., Zboril R., Schneeweiss O., Zeman J., Cernik M., Kvapil P., Otyepka M., 2007. Environmental applications of chemically pure natural ferrihydrite. Environ. Sci. Technol. 41, 4367-4374.

Garrido-Ramirez, E.G., Theng, B.K.G., Mora, M.L. 2010. Clays and oxide minerals as catalysts and nanocatalysts in Fenton-like reactions - A review. Appl. Clay Sci. 47, 182-192.

Garrido-Ramirez, E.G., Mora, M.L., Marco, J.F., Ureta-Zanartu, M.S. 2013. Characterization of nanostructured allophane clays and their use as support of iron species in a heterogeneous electro-Fenton system. Appl. Clay Sci. 86, 153-161.

Goure-Doubi, H., Martias, C., Lecomte-Nana, G.L., Nait-Ali, B., Smith, A., Thune, E., Villandier, N., Gloaguen, V., Soubrand, M., Konan, L.k. 2014. Interfacial reactions between humic-like substances and lateritic clay: Application to the preparation of "geomimetic" materials. J. Colloid Interface Sci. 434, 208-217.

Guo, H., Barnard, A.S. 2013. Naturally occurring iron oxide nanoparticles: morphology, surface chemistry and environmental stability. J. Mater Chem. A $1,27-42$.

Gregor, C., Hermanek, M., Jancik, D., Pechousek, J., Filip, J., Hrbac, J., Zboril, R., 2010. The effect of surface area and crystal structure on the catalytic efficiency of iron(III) oxide nanoparticles in hydrogen peroxide decomposition. Eur. J. Inorg. Chem. 16, 2343-2351

Haber, F., Le Rossignol, R. 1916. U.S. patent number 1202995 A. United States Patent Office.

He, H., Zhong, Y., Liang, X., Tan, W., Zhu, J., Wang, C.Y. 2015. Natural magnetite: an efficient catalyst for the degradation of organic contaminant. Sci. Reports. 5 10139, 1-10.

Kakuta, S., Okayama, T., Kato, M., Odab, A., Abe, T. 2011. Clarification of photocatalysis induced by iron ion species naturally contained in a clay compound. Catal. Sci. Technol. 1, 1671-1676 
Ko, T.H., Chu, H., Tseng, J.J. 2006. Feasibility study on high-temperature sorption of hydrogen sulfide by natural soils. Chemosphere $64,881-891$.

Ko, T.H. 2008. Removal of hydrogen sulfur from coal-derived gas by iron oxides in various Oxisols. Environ. Eng. Sci. 25 969-973.

Kong, S.H., Watts, R.J., Choi, J.H. 1998. Treatment of petroleum-contaminated soils using iron mineral catalyzed hydrogen peroxide. Chemosphere. 37, 1473-1482.

Kwan, W.P., and Voelker, B.M. 2003. Rates of hydroxyl radical generation and organic compound oxidation in mineral-catalyzed Fenton-like systems. Environ. Sci. Technol. 37, 1150-1158.

Lackhoff, M., and Niessner, R. 2002. Catalytic atrazine degradation by synthetic minerals, atmospheric aerosols, and soil particles. Environ. Sci. Technol. 36, 5342-5347.

Lan, S., Wang, X., Xiang, Q., Yin, H., Tan, W., Qiu, G., Liu, F., Zhang, J., Feng, X. 2017. Mechanisms of $\mathrm{Mn}$ (II) catalytic oxidation on ferrihydrite surfaces and the formation of manganese (oxyhydr) oxides. Geochim. Cosmochim. Acta. 211, 79-96.

Latifi, M., Berruti, F., Briens, C. 2017. Jiggle bed reactor for testing catalytic activity of olivine in biooil gasification. Powder Technol. 316, 400-409.

Lima, H., Lee, J., Jin, S., Kim, J., Yoon, J., Hyeon, T. 2006. Highly active heterogeneous Fenton catalyst using iron oxide nanoparticles immobilized in alumina coated mesoporous silica. Chem. Commun. 4, 463-465.

Lima, L.V.C, Rodriguez, M., Freitas, V.A.A., Souza, T.E., Machado, A.E.H., Patrocínio, A.O.T., Fabris, J.D., Oliveira, L.C.A., Pereira, M.C. 2015. Synergism between n-type $\mathrm{WO}_{3}$ and p-type $\delta$-FeOOH semiconductors: High interfacial contacts and enhanced photocatalysis. Appl. Catal. A Environ.165, 579-588.
Lu, M.C., Chen, J.N., Huang, H.H. 2002. Role of goethite dissolution in the oxidation of 2-chlorophenol with hydrogen peroxide. Chemosphere, 46, 131-136.

Liu, H., Chen, T., Frost, R.L. 2014. An overview of the role of goethite surfaces in the environment. Chemosphere. 103, 1-11.

Machala, L., Tuček J., Zbořil R., 2011. Polymorphous transformations of nanometric iron(III) oxide: a review. Chem. Mater. 23, 3255-3272.

Mammeri, L., Sehili, T., Belaidi, S., Djebbar, K. 2015. Heterogeneous photodegradation of 1-naphthol with natural iron oxide in water: influence of oxalic acid. Desalin. Water Treat. 54, 2324-2333.

Manzo, V., Pizarro, C., Rubio, M.A., Cavalcante, L.C., Garg, V.K., Fabris, J.D. 2011. Preparative treatment with $\mathrm{NaOH}$ to selectively concentrate iron oxides of a Chilean volcanic soil material to produce effective heterogeneous Fenton catalyst Hyperfine Interact. 203, 59-66.

Matta, R., Hanna, K., Kone, T., Chiron, S. 2008. Oxidation of 2,4,6-trinitrotoluene in the presence of different iron-bearing minerals at neutral $\mathrm{pH}$. Chem. Eng. J. 144, 453458.

McKeague, J. M., Day, J. H. 1966. Dithionite and oxalate-extractable $\mathrm{Fe}$ and $\mathrm{Al}$ as aids in differentiating var $\neg$ ious classes of soils. Can. J. Soil Sci. $46,13-22$.

Mechakra, H., Sehili, T., Kribeche, M.A., Ayachi, A.A., Rossignol, S., George, C. 2016. Use of natural iron oxide as heterogeneous catalyst in photo-Fenton-like oxidation of chlorophenylurea herbicide in aqueous solution: Reaction monitoring and degradation pathways. J. Photoch. Photobio A. 317, 140-150.

Mehra, O.P., Jackson, M.L. 1958. Iron oxide removal from soils and clays by a dithionite-citrate system buffered with sodium bicarbonate in: Clays and 
Clay Minerals, Procedings of the 7th National Conference, Washington, D.C., pp. 317-327.

Mella, A., Kühne, A., 1985. Sistemática y descripción de las familias, asociaciones y series de suelos derivados de materiales piroclásticos de la zona central sur de Chile, in: J. Tosso (Ed.), Suelos volcánicos de Chile, INIA, Santiago pp. 570-712.

Moya, S.A., Flores, A., Escudey, M., Venegas, R., Castello, G., Latorre, R. 1991a. Mossbauer spectroscopy for the characterization of soils used as catalysts. Hyperfine Interact. 67, 581-586.

Moya, S.A., Flores, A., Escudey, M. 1991b. Soils as unusual catalyst. Preparation of Catalyst V, in: Studies in Surface Science and Catalysis (Ed.), vol. 63, pp. 279-286.

Navia, R., Fuentes, B., Diez, M.C., Lorber, K.E. 2005b. The use of volcanic soil as mineral landfill liner - III. Heavy metals retention capacity. Waste Man. Res. 23: 260-269.

Nidheesh, P.V. 2015. Heterogeneous Fenton catalysts for the abatement of organic pollutants from aqueous solution: a review. RSC Adv., 2015, 5, 4055240577.

Norrish, K., Taylor, R.M. 1961. The isomorphous replacement of iron by aluminium in soil goethites. J. Soil Sci. 12, 294-306.

Oliveira, L.C.A., Fabris, J.D., Pereira., M.C. 2013. Oxidos de ferro e suas aplicazoes em processos cataliticos: Uma revisao. Quim. Nova 36, 123-130.

Pereira, M.C., Tavares C.M., Fabris J.D., Lago R.M., Murad E., Criscuolo P.S. 2007. Characterization of a tropical soil and a waste from kaolin mining and their suitability as heterogeneous catalysts for Fenton and Fenton-like reactions. Clay Miner. 42, 299-306.

Pereira, N.C., Cavalcante, L.C., Magalhaes, F., Fabris, J.D., Stucki, J.W., Oliveira, L.C.A., Murad, E. 2011. Composites prepared from natural iron oxides and sucrose: A highly reactive system for the oxidation of organic contaminants in water. Chem. Eng. J. 166, 962-969.

Pereira., M.C., Oliveira, L.C.A., Murad, E., 2012. Iron oxide catalysts: Fenton and Fenton- like reactions a review. Clay Miner. 47, 285-302.

Pham, A.L.T., Doyle, F.M., Sedlak, D.L. 2012. Kinetics and efficiency of $\mathrm{H} 2 \mathrm{O} 2$ activation by ironcontaining minerals and aquifer materials. Water Res. 46, 6454-6462.

Pizarro C., Furet N. R., Venegas R., Fabris J. D., Escudey M. 2000a. Some caution on the interpretation of Mössbauer spectra in mineralogical studies of volcanic soils. Bol. Soc. Chil. Quím., 45, 243-250.

Pizarro C., Escudey M., Fabris J. D., Almeida A. B. 2000b. Effects of sodium hydroxide selective chemical treatment on sample from some Chilean soils. Commun. Soil Sci. Plant Anal. 31, 31133119

Pizarro C., Escudey M., Fabris J. D. Almeida A. B. 2001. Iron-rich spinel phases from the sand fraction of three Chilean soils developing on volcanic materials. Commun. Soil Sci. Plant Anal. 32, 2741-2754.

Pizarro C., Escudey M., Fabris J. D. 2003. Influence of organic matter on the iron oxides mineralogy of volcanic soils. Hyperfine Interact. 148, 53-59.

Pizarro C., Escudey M., Moya S.A., Fabris J.D. 2005. Iron oxides from volcanic soils as potential catalysts in the water gas shift reaction. Proceedings from the International Symposium of the Industrial Application of the Mössbauer Effect. American Institute of Physic Proceedings. 765, 56-59.

Pizarro C., Fabris J. D., Stucki J., Garg V. K., Morales C., Aravena S., Gautier J. L., Galindo G. 2008. Distribution of Fe-bearing compounds in an Ultisol as determined with selective chemical dissolution and Mössbauer spectroscopy. Hyperfine Interact. 175, 95-101. 
Pizarro, C., Escudey, M., Gacitua, M., Fabris, J.D. 2017. Iron-bearing minerals from soils developing on volcanic materials from southern Chile. Mineralogical characterisation supported by Mössbauer spectroscopy. J. Soil Sci. Plant Nutr. 17, 341-365.

Prucek, R., Hermanek, M., Zboril, R. 2009. An effect of iron(III) oxides crystallinity on their catalytic efficiency and applicability in phenol degradation-A competition between homogeneous and heterogeneous catalysis. Appl. Catal. A-Gen. 366, 325-332.

Redel, Y. Cartes, P., Demanet, R., Velásquez, G., Poblete-Grant, P., Bol, R., Mora, M.L. 2016. Assessment of phosphorus status in uenced by $\mathrm{Al}$ and Fe compounds in volcanic grassland soils. J. Soil. Sci. Plant Nutr. 16, 490-506.

Roy, M., Naskar, M.K. 2016. Alkali metal ions induced cube shaped mesoporous hematite particles for improved magnetic properties, and efficient degradation of water pollutant. Phys. Chem. Chem. Phys. DOI: 10.1039/C6CP02442D.

Rzepa, G., Bajda, T., Gawel, A., Debiec, K., Drewniak, L. 2016. Mineral transformations and textural evolution during roasting of bog iron ores. $\mathrm{J}$. Therm. Anal. Calorim. 123, 615-630.

Scopus. 2017. Scopus - Document search. Elsevier. Available at: https://www.scopus.com/home.uri (accessed august 1st 2017).

Silva, A.C., Escudey, M., Förster, F.E., Pizarro, C., Ardisson, J.D., Barral, U.M., Pereira, M.C., Fabris, J.D. 2014. Iron-bearing minerals in ashes emanated from Osorno volcano, in Chile. Hyperfine Interact. 224, 153-159.

Souza, W.F., Guimaraes, I.R., Lima, D.Q., Silva, C.L.T., Oliveira, L.C.A. 2009. Brazilian limonite for the oxidation of quinoline: high activity after a simple magnetic separation. Energ. Fuel. 23, 4426-4430.
Temkin, M.I. 1979. The kinetics of some industrial heterogeneous catalytic reactions. In: Advances in Catalysis; Eley, D. D., Pines, H., Weisz, P. B., Eds.; Academic Press: New York, Vol. 28; pp 173.

Torres-Sanchez, R.M. and Tavani, E.L.1994. Temperature effects on the point of zero charge and isoelectric point of a red soil rich in kaolinite and iron minerals. J. Therm. Anal. 41, 1129-1139.

U.S. Department of Agriculture, Natural Resources Conservation Service. 2006. The twelve orders of Soil Taxonomy. Available at: https:// www.nrcs.usda.gov/wps/portal/nrcs/detail/soils/ edu/?cid=nrcs142p2_053588 (accessed may 5th 2017).

Vicente, F., Rosas, J.M., Santos, A. Romero, A. 2011. Improvement soil remediation by using stabilizers and chelating agents in a Fenton-like process. Chem. Eng. J. 172, 689-697.

Wang, G., Xu, S., Jiang, L., Wang, C. 2016. Nickel supported on iron-bearing olivine for $\mathrm{CO}_{2}$ methanation. Int. J. Hydrogen Energ. 41, 12910-12919.

Xiang, Q.Y., Cao, J.L., Li, Y., Huang, Y.L., Shi, Y., Wang, J., Mo, L.B., Yao, W.Q. 2016. A green, low-cost and efficient photocatalyst: Atomichydrogenated $\delta-\mathrm{Fe}_{2} \mathrm{O}_{3}$. Catal. Surv. Asia. 20, 133140 .

Yang, S., He, H., Wu, D., Chen, D., Liang, X., Qin, Z., Fan, M., Zhu, J., Yuan, P. 2009. Decolorization of methylene blue by heterogeneous Fenton reaction using $\mathrm{Fe}_{3-\mathrm{x}}-\mathrm{Ti}_{\mathrm{x}} \mathrm{O}_{4}(0 \leq \mathrm{x} \leq 0.78)$ at neutral pH values. Appl. Catal. B-Environ. 89, 527-535.

Yu, M., Teel, A.L., Watts, R.J. 2016. Activation of peroxymonosulfate by subsurface minerals. J. Contam. Hydrol. 191, 33-43.

Zhu, M., Wachs, I.E. 2016. Iron-Based catalysts for the high-temperature water-gas shift (HT-WGS) reaction: A review. ACS Catal. 6, 722-732. 
Zhong, Y., Liang, X., Zhong, Y., Zhua, J., Zhu, S., Yuan, P., Hea, H., Zhang, J. 2012. HeterogeneousUV/Fenton degradation of TBBPA catalyzed by titanomagnetite: Catalyst characterization, performance and degradation products. Water Res. 46, 4633-4644.
Zhu, M., Wachs, I.E. 2016. Iron-Based catalysts for the high-temperature water-gas shift (HT-WGS) reaction: A review. ACS Catal. 6, 722-732. 